Bull. Fac. Agric., Cairo Univ., 70:53-68 (2019).

\title{
ANALYTICAL STUDY OF THE FEASIBILITY OF SOME VEGETABLE CROPS CULTIVATION UNDER CONDITIONS OF MODERN AGRICULTURE IN RED SEA GOVERNORATE
}

(Received: 27.6.2019)

\author{
By \\ M. A. E. A. Mahaba and M. O. A. Mohamed \\ Department of Economic Studies, Socio-Economic Division, Desert Research Center, Cairo
}

\begin{abstract}
Greenhouses are important input for agricultural investment in the field of plant production, especially the vegetable crops produced in non-production seasons due to modern and advanced technologies .Greenhouses are one of the means to raise the economic efficiency of the agricultural land and irrigation water units, characterized by high productivity compared to agriculture in the open field. In addition, agriculture in the greenhouses overcomes seasonality of production and provides protection of crops against climatic fluctuations, as well as raising the efficiency of water use, where it save between $30-50 \%$ of the amount of irrigation water, which contributes to its spread in different areas ,especially those that suffer water scarcity such as the Arab Republic of Egypt, in particular the desert areas, such as the Red Sea Governorate.The project uses modern technologies in agricultural production such as electricity generation from solar energy and desalination of well water in the production of cucumber and colored peppers in 10 greenhouses, is 350 square meters, (width of 10 meters and length of 35 meters). The total fixed costs of the project, amounted to LE 1,108366 million. The total annual operating costs amounted to LE 200,125. The total annual revenues amounted to LE 737 thousand. The results of the study showed that all the financial indicators were positive and encouraging, which necessitates continued investment in the project. The project is expected to achieve a return rate of $40.82 \%$, which exceeds the prevailing market rate of about $16 \%$.The project will be able to cover the invested capital during 2.39 years only, within 15 years as the default age of the project. The project was subjected to financial analysis under unfavorable conditions such as reduced revenues or raised total project costs, whether investment operating maintenance costs, or shortening the project duration where the financial indicators of the project showed positive and encouraging results, which necessitates continuing the decision to invest in the project.

The study reached a lot of results as follows :

- Design guiding programs for farmers on the importance of greenhouses use and economic feasibility.

- The New and Renewable Energy Authority will design and publish guiding programs for the importance of the use of solar energy technology to provide electricity, especially to serve the desert areas away from the public electricity grid.

- The Ministry of Irrigation and Water Resources is spreading awareness about the use of well water desalination technology in desert and coastal areas.

- The State shall attract and stimulate the private sector to invest in the field of solar energy and desalination.

- The Egyptian Agricultural Bank provides soft loans for the purpose of establishing greenhouses.

- Attracting investors and young graduates to expand the use of greenhouses techniques, especially in desert areas.

- Linking the idea of investment in greenhouses with the policy of contractual agriculture.
\end{abstract}

Key words: greenhouses, vegetable crops and feasibility study. 
دراسة تحليلية لجدوى زراعة بعض محاصيل الخضر تحت ظروف الزراعات الحديثة فى محافظة البحر الأحمر

مهابه عبد المعطى السيد أحمد مهابهـ محمد عمر عبد العزيز محمد

قسم الدر اسات الاقتصادية ـ شعبة الدر اسات الاجتماعية و الاقتصادية ـ مركز بحوث الصحر اءـالمطرية ـ القاهرة

تعتبر الصوب الزراعية مدخلا هاما للاستثمار الزراعي في مجال الإنتاج النباتي وخاصة محاصيل الخضر

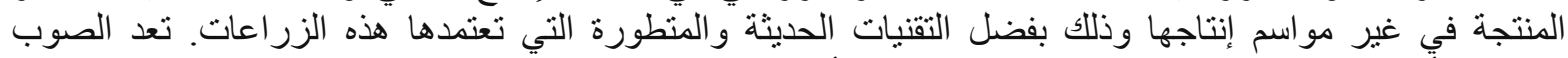

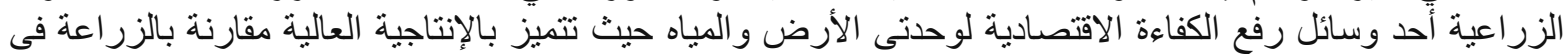

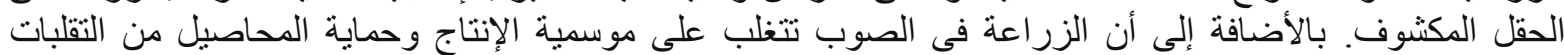

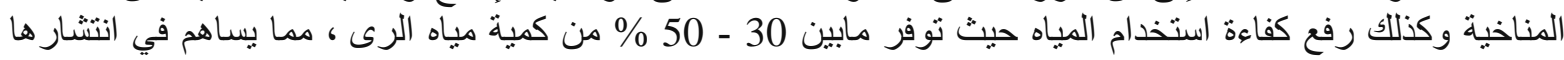

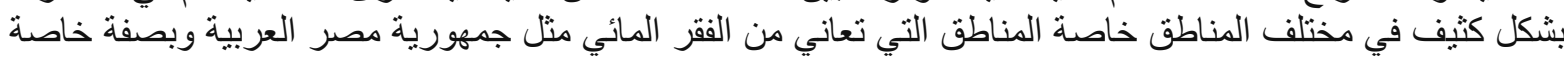

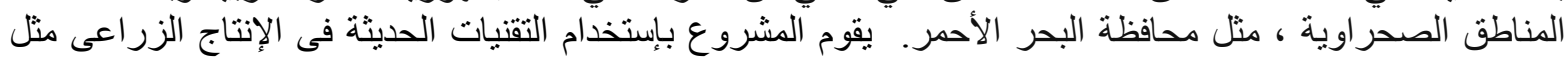

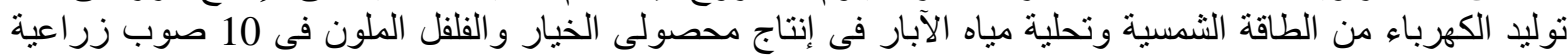

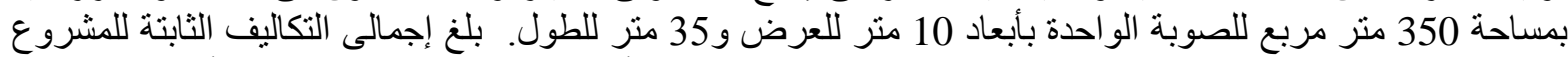

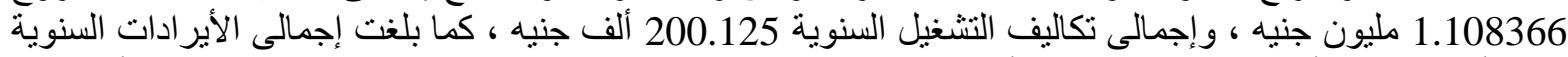

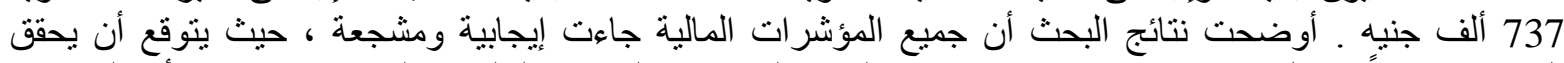

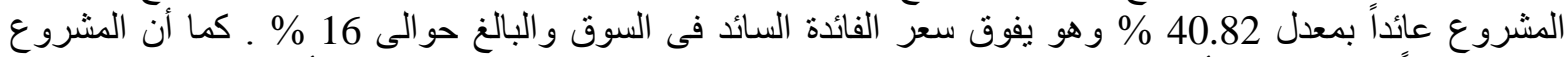

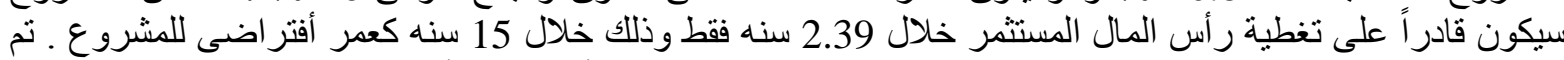

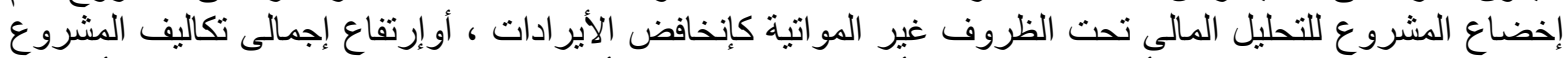

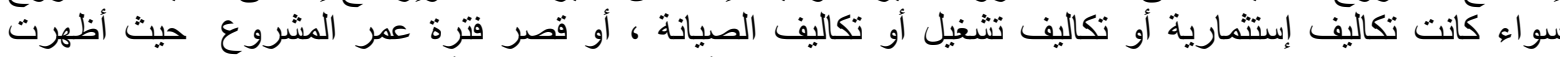

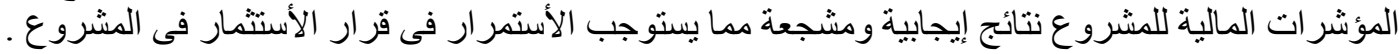

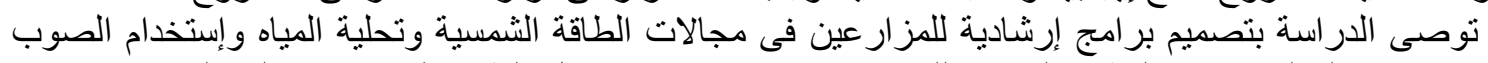

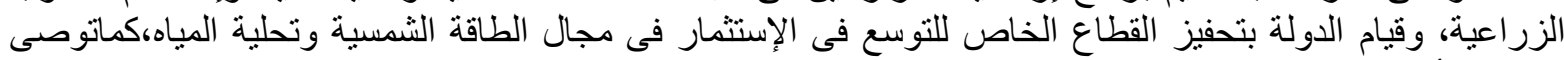

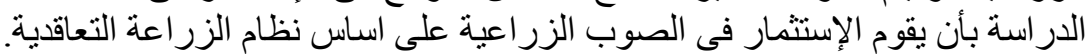

من كمية مياه الرى (زكى في من 2010) ، مما يساهم في

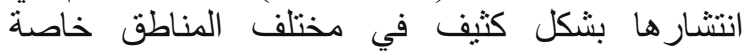

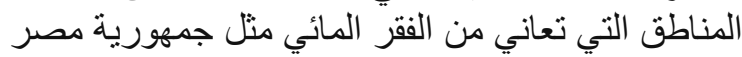

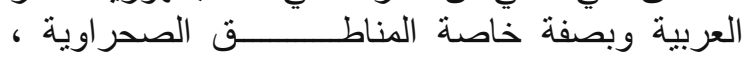

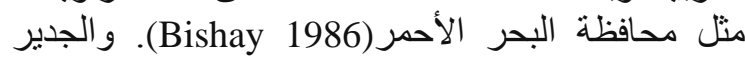

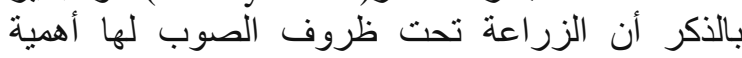

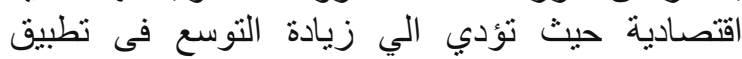

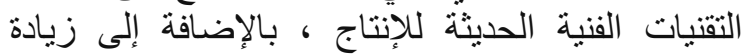

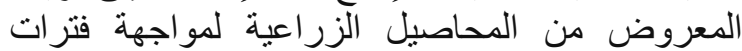

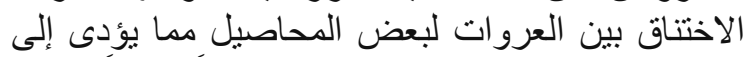

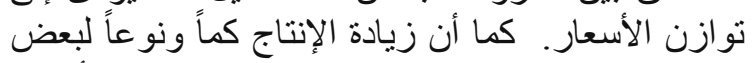

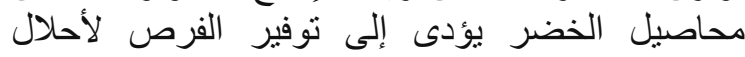
المحاصيل التقليدية فى المساحات التى كانت تشيل تشغلها تللك لألى

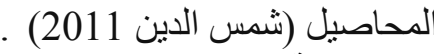

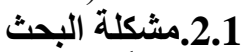

نظراً للمسئولية الكبيرة الملقاه على عاتق القطاع

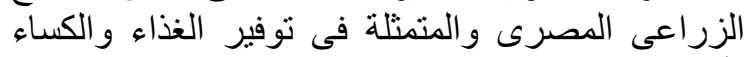

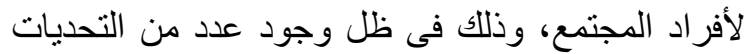

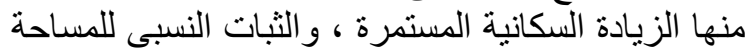

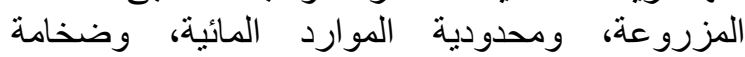

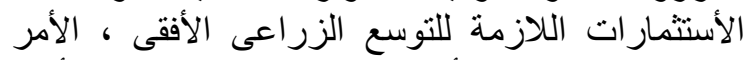

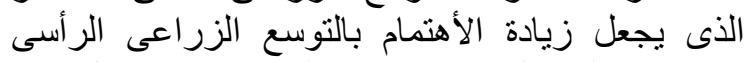

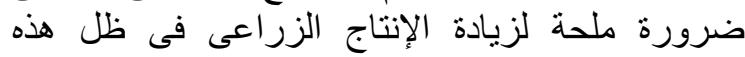

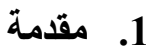

1.1

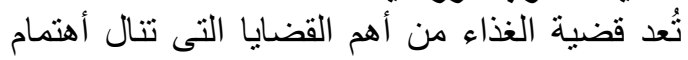

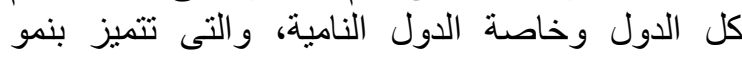

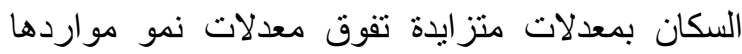

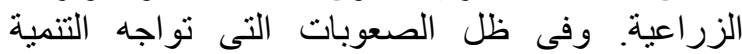

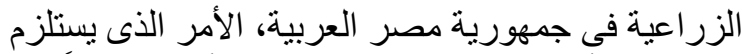

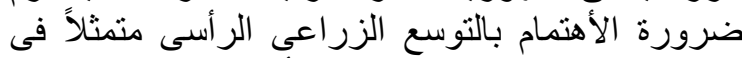

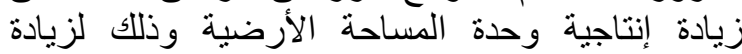

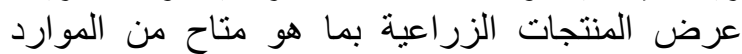

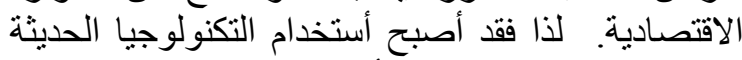

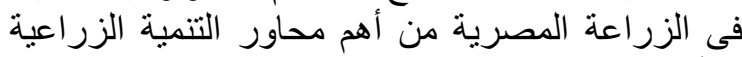

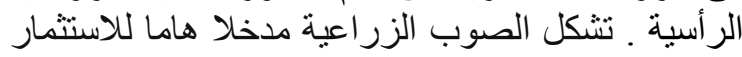
الزراعي في مجال الإنتاج النباتي وخاصة الزية محاصيل فيليل

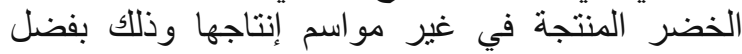

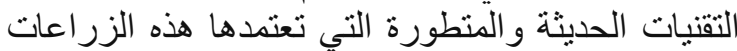

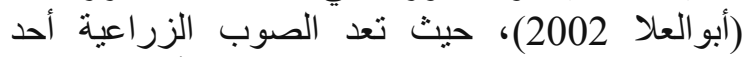

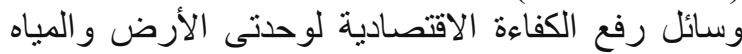

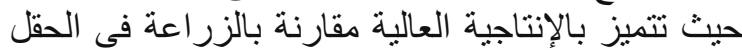

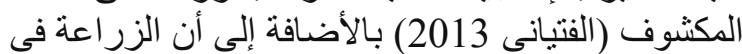

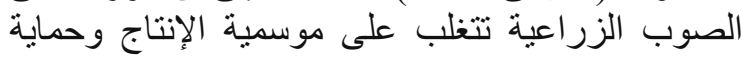

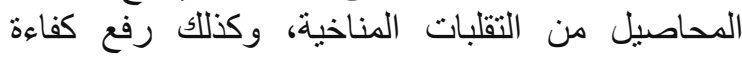
استخدام المياه حيث توفر مابين 30 - 50 \% وكنات 


\section{3. النتائج البحثية ومناقشتها}

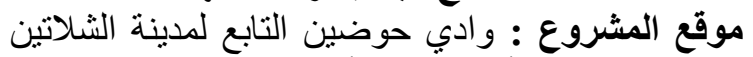

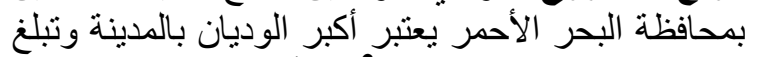

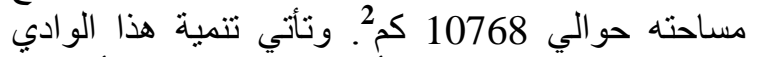
ضمن استر اتيجية التوسع الأفقي في أستصلاح الأراضي التئي

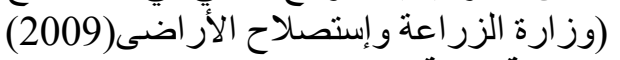
الدراسة الفنية للمشروع الزونة يتكون المشروع من أربعة وحدات رئيسية نشمل

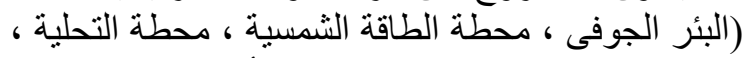

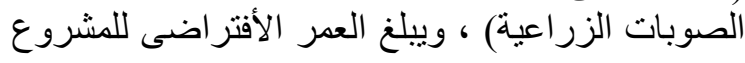

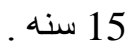

أولاً: البئر الجوفى : يعتبر وادي حوضين التابع لمدينة

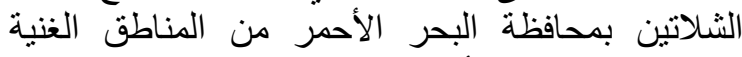

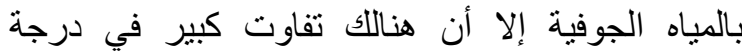

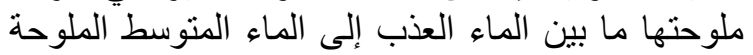

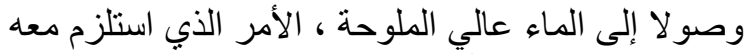

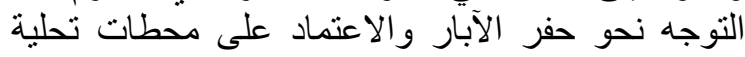

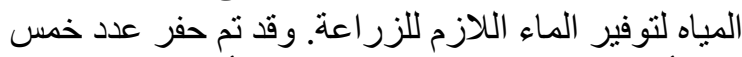

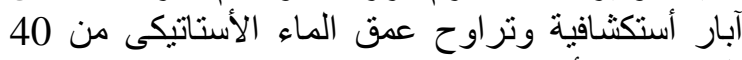

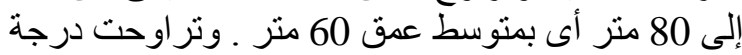

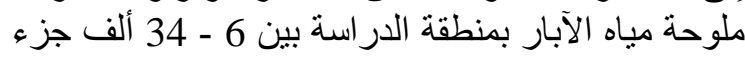

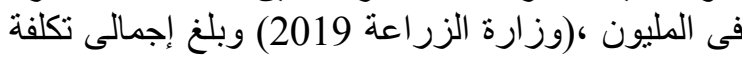

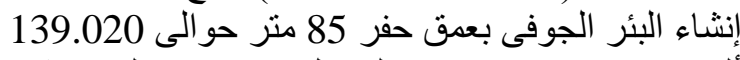
ألف جنيه ، وتوضح بيانات الجدول رقفم (1) تكاليف إنشاء

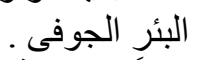
ثانياً : محطة الطاقة الثمسية : تتمتع جمهورية مصر

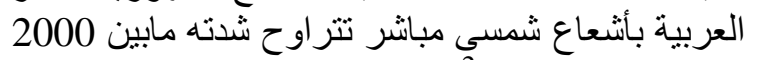

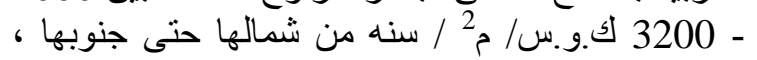

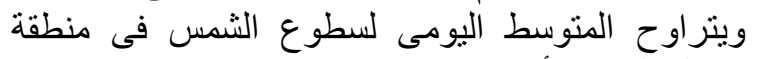

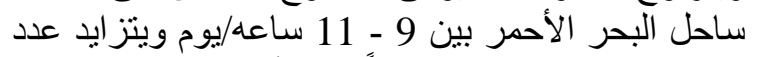

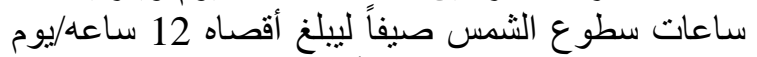

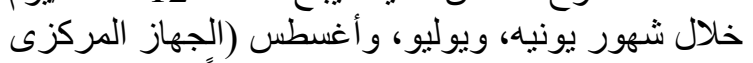

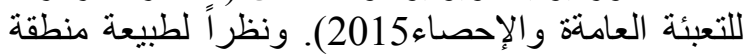

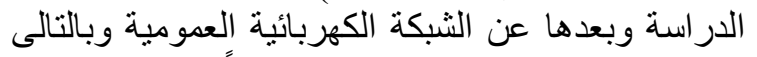

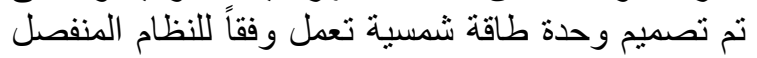

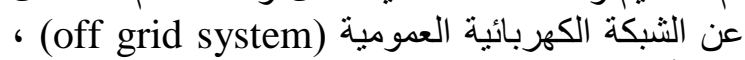
ويتم أستخدام تقنية الفوتو فولطية (P.V) و التي تستخدم

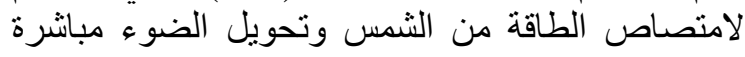

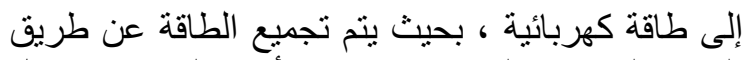

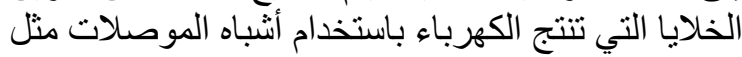

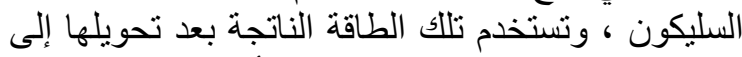
تيار مثردد باستخدام عاكس التيار أو يتم تخزينها في بـاني

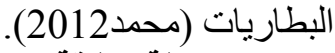

\section{مكونات محطة الطاقة الثمسية :}

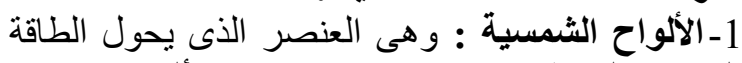

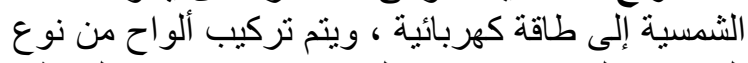

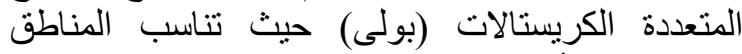

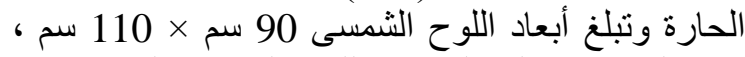

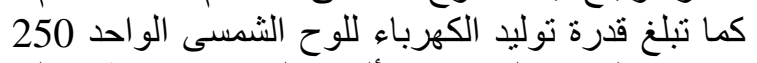
وات. ويبلغ إجمالى عدد الألواح الثمسية بمحطة توليد الواحة
التحديات القائمة ـ. وبالتالى كان الإتجاه للزر اعة المحمية

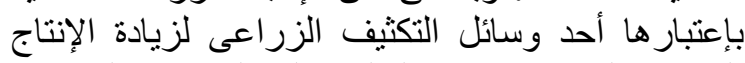

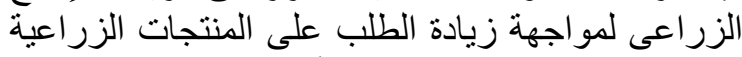

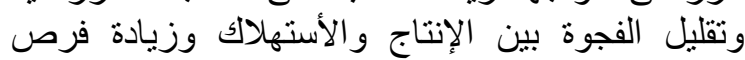

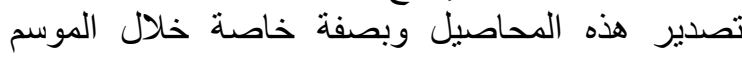

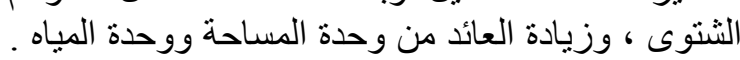

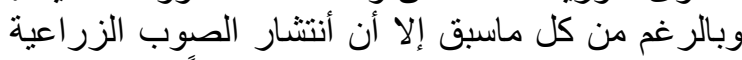
فى جمهورية مصر العربية لا يز الئ ال محدوداً.

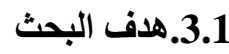

يستهوف البحث بصفة رئئية تشجيع المستثرين

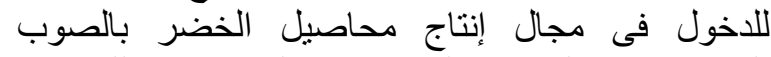

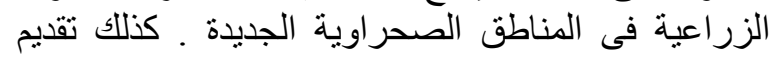

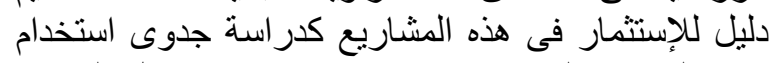

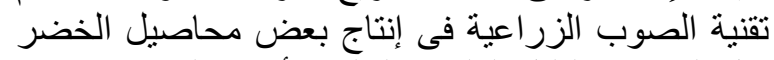

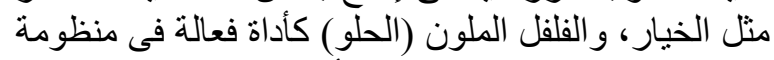

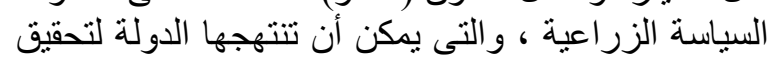

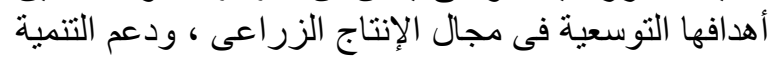

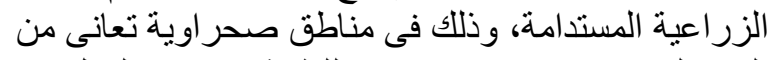

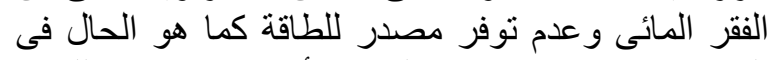

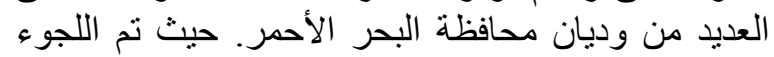

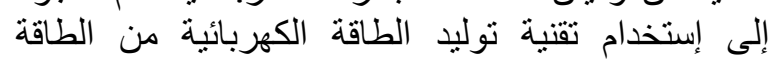

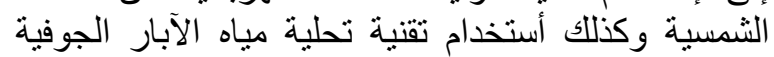

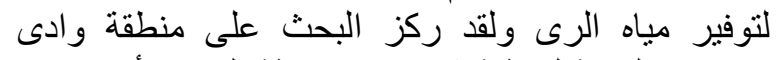
حوضين التابعة لمنطقة شلاتثين بمحافظة البحر الأحمر.

\section{2. الطريقة البحثية ومصادر البيانات}

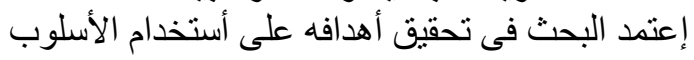

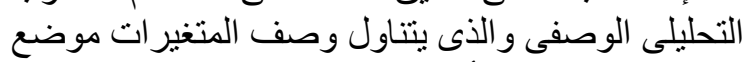

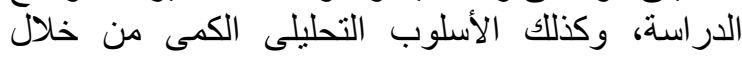
استخدام المقاييس غير المخصومة لإر اسة الجدوى مثلى منل

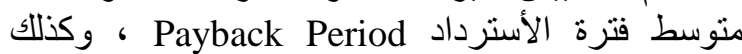

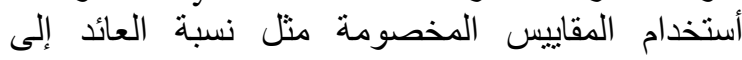

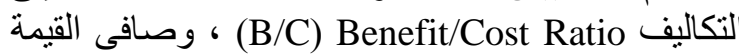

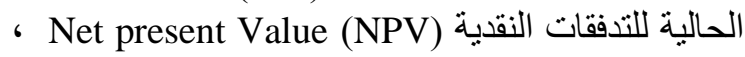
Internal Rate Of Return ومعدل العائد الاخلية

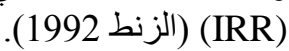
وأعتمد البحث في تحقيق أهدافه على مصدرين

$$
\text { للبيانات هما : البان البنات }
$$

ـ البيانات الثانوية المنشورة و غير المنشورة من مصادرها

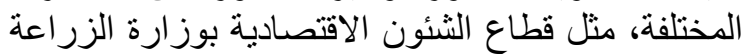

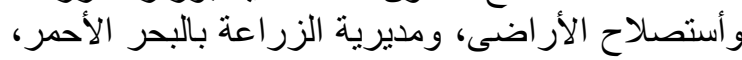

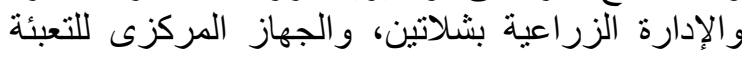

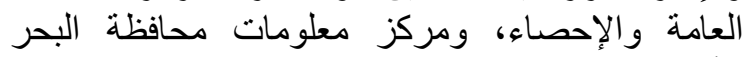
الأحمر، بالإضافة إلى بعض الإحرة المراجع العربية والإجنبية

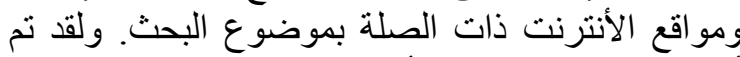

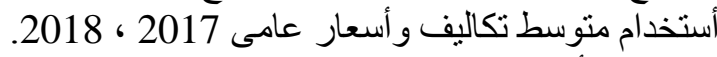

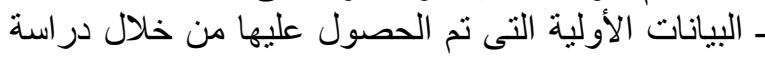

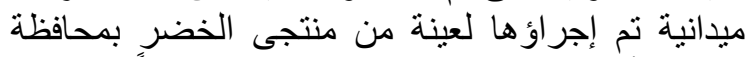

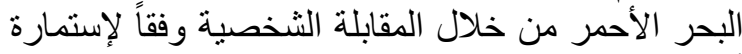
أستبيان صممت لهذا الغرض . لأل الغقابل 


\begin{tabular}{|c|c|c|c|c|}
\hline (جنيه) الإجمالى & الوحدة & الوحدات & بيان & م \\
\hline 19125 & 225 & 吾 85 & أجرة الحفر & 1 \\
\hline 23800 & 280 & 85 & مو اسير جسم البئر (10 بار ، قطر 11 بوصة) & 2 \\
\hline 500 & 500 & 1 & مياه (لتسهيل عملية الحفر - جرار 20 م³) & 3 \\
\hline $\begin{array}{c}600 \\
200 \\
195 \\
1500\end{array}$ & $\begin{array}{c}400 \\
200 \\
65\end{array}$ & $\begin{array}{c}1.5 \\
1 \\
3\end{array}$ & 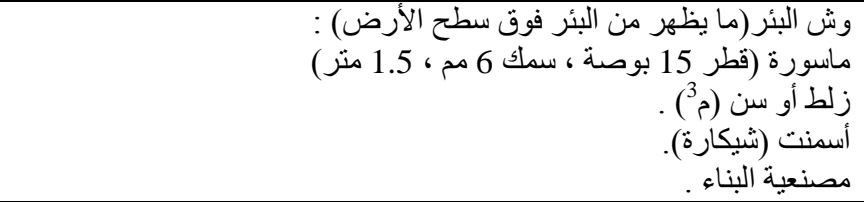 & 4 \\
\hline 2000 & & & أكر اميه عمال الحفر & 5 \\
\hline 13500 & 325 & 60 & مو اسير سملس صب (قطر 4 بوصة لزوم تركيب طلمبة الأعماق) & 6 \\
\hline 24300 & 180 & 135 & كبل بحرى (يمد الطلمبة فى عمق البئر بالطاقة الكهربائية) & 7 \\
\hline 15000 & & 1 & طلمبة أعماق (قرة 10 حصان - 9 مر احل) & 8 \\
\hline 18000 & 300 & 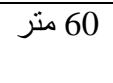 & خط المو اسير الر ابط بين طلمبة الأعماق ووش البئر (قطر 5 بوصة ، سمك 6 & 9 \\
\hline 6500 & & & لوحة تشغيل كهربائية & 10 \\
\hline 5000 & & & أجرة تركيب (طلمبة الأعماق ، المو اسير ، لوحة التشغيل) & 11 \\
\hline 6800 & & & أجرة نقل وتحميل & 12 \\
\hline 2000 & & & مصاريف نثرية أخرى & 13 \\
\hline $\mathbf{1 3 9 0 2 0}$ & & & 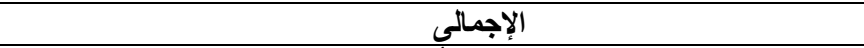 & \\
\hline
\end{tabular}

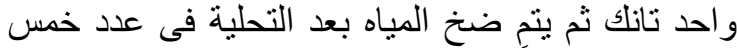

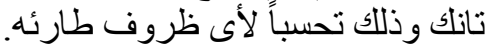

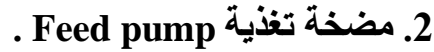

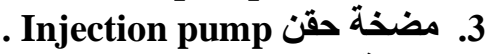

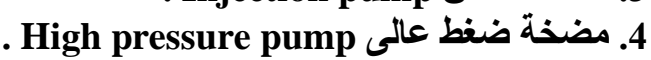

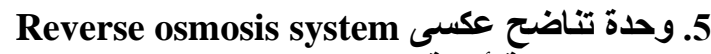

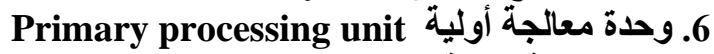
7. 6وحة معالجة نهائية Secondary processing unit

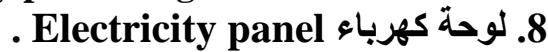
وقدر إجمالى تكلفة وحدة التحلية بمبلغ 300 ألف وتقدر إجمالى المساحة اللازمة لبئر الماء الجوفى المئ ومحطة الطاقة الثمسية ومحطة التحلية و إقامة عدد 6

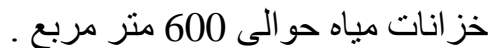

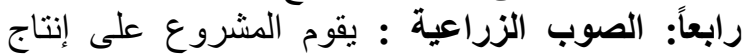

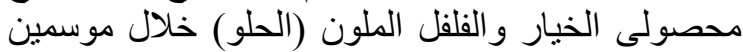
زراعيين الأول لإنتاج الخيار، والموسم الثانى لإنتاج

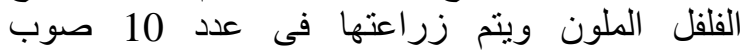
بلاستيكية، حيث تبلغ مساحة الصوبة الواحدة 350 متر فئر

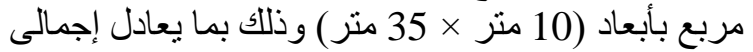

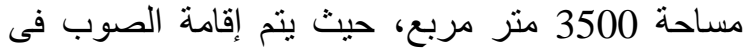
صفين متقابلين كل صف بـاه 5 صوبات ويتم ترك مك مسافة 3.5 متر بين الصفين كممر لتسهيل عمليات تركيب الشبكة الخاصة بالرى و القيام بعملية التسميد و وشئ رئ المبيدات ونقل وجمع المحصول، كما يتم ترك لك مسافة 1.5 متر بين كل صوبتين متجاورتين ، وبالتالى فإن إجمالى لـ الى

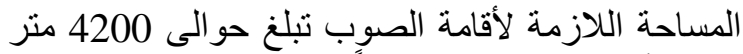

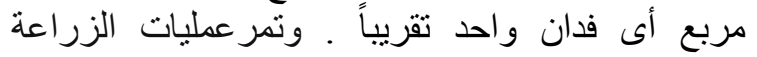

الطاقة الكهربائية 44 لوح شمسى تكفى لتوليد 11 كيلو وات / ساعه. 2-حوامل التثبيت : هيكل التثبيت من الألومنيوم عالي

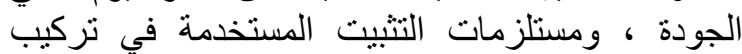

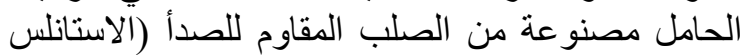
ستيل) ، ويتم التركيب بالمسامير مما يجعله سهل الفل الفك

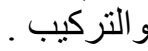

3. كابلات كهربائية .

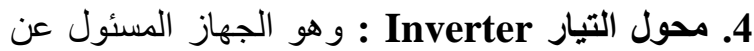

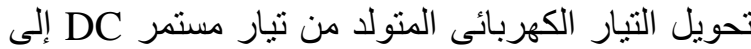
تيار متردد AC لكى يناسب عمل الأجهزة التى يتم توصيلها عليه (وزارة الكهرباء والطاقة 2010-2017) . وتم تصميم وحدة الطاقة الشمسية بقدرة 11 كيلو وات اتهاء / ساعه لكى تتناسب قدرتها مع أحتياجات تشغيل البئر الجوفى ووحدة التحلية ، وقدر إجمالى تكلفة وحدة الطاقة

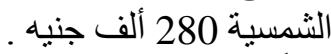

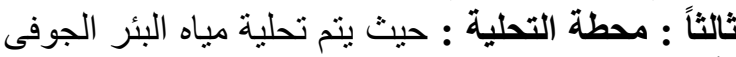

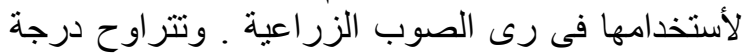

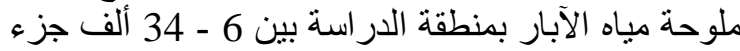

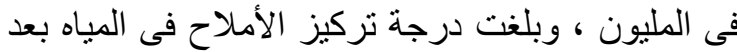

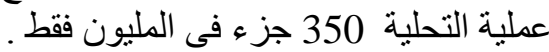
وتتكون محطة التحلية من :

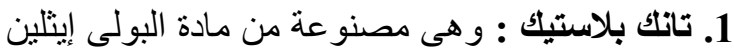

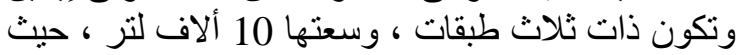

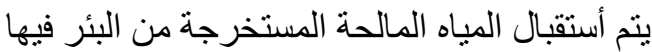

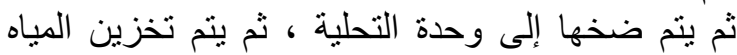

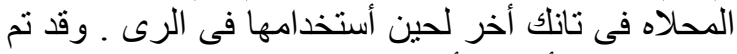

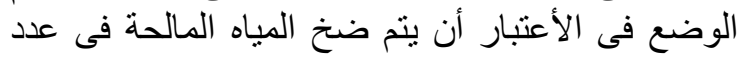




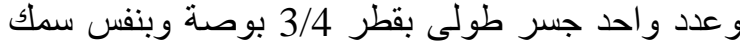
القوس وتكلفه هذه الصوبة بالمو اصفات السابقة يقدر بنحو

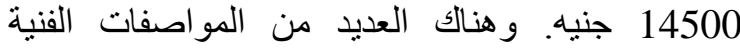

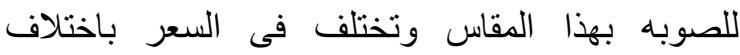
المواصفات، وبالتالى تكون القيمة الاجمالية لعدد 10

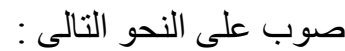
عدد 10 صوب = 10 × 145000 جنيه النيه 14500 جنيه

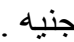

2- الغطاء البلاستيكى: يلزم لإنشاء صوبة زر اعية بأبعاد

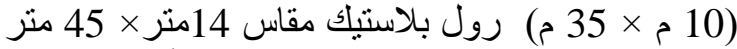

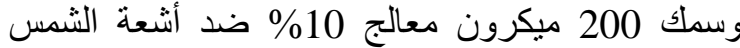
الفوق بنفسجية وييلغ سعر الكيلو جرام 52.6 جنئهيه، و الصوبة الواحدة يلزمها 136 كجم بلاستيك، فيكون الون اجمالى تكلفة الصوبة الواحدة 136 كجم × 52.6 جنية 52.6 جنيه

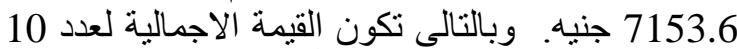
صوب نحو 71536 جنيه علماً بأنه يتم تغيير الاجيه لغطاء

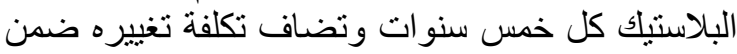

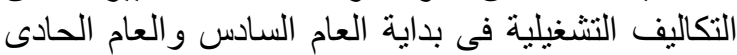

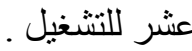

3- السلتك المجلفن او كبل الثد بين الاقواس وبعضها:

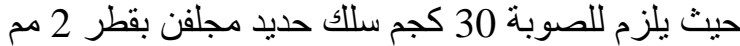
بسعر 21 جنيه للكيلو فيكون إجمالى تكلفة الصوبة 30 لكوبة

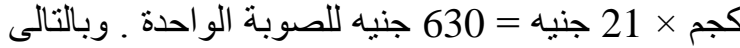

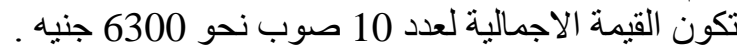

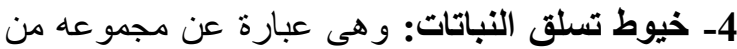

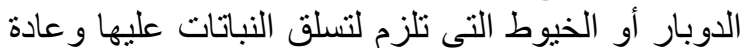

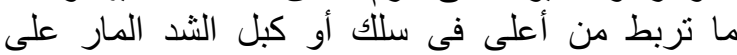

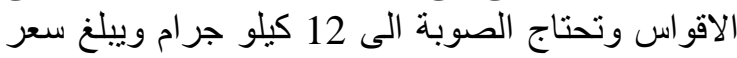

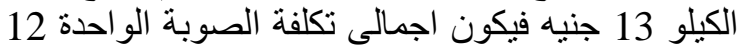

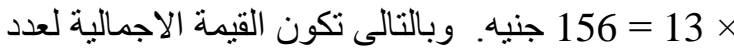

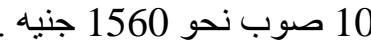

5- الأبواب الخاصة بالصوب: غالباً ما تصنع من الحديد

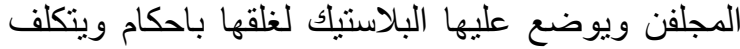

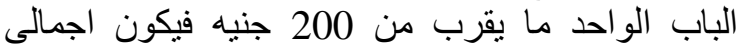
البابين لكل صوبة 400 جنيه وبالتالى تكون القيهة 6-الاجمالية لعدد 10 صوب ندوبة نحو 4000 جنيه . 6-أجرة تركيب الصوب: تتكلف أجرة تركيب الصوبة الصنا

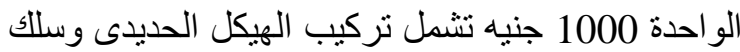

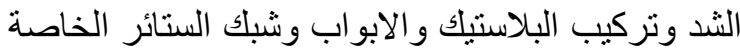

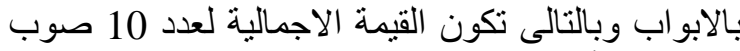
حو الي 10 ألاف جنيه. 7- أجرة الأشراف على التركيب: حوالي 300 جنيه

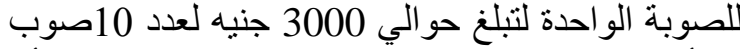
8- أجرة نقل الصوب والبلاستيك : و هذا البند لابد من أن أن الني

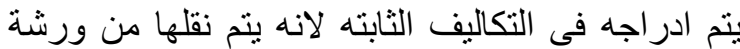

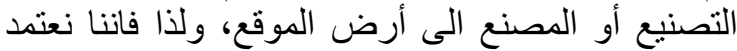

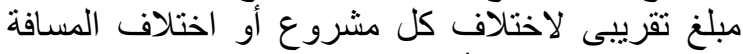

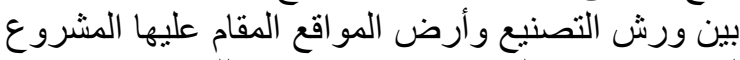

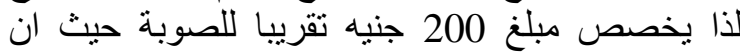
المناطق الصحر اوية تزيد فيها تكلفة النقل، وبالتالى تكون لتحن
الزحمية بعدة مراحل بدءً بتحضير الصوبة ومرورا بزر اعة المحاصيل و التسميد و الري ولئة والمكافحة .

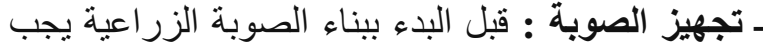

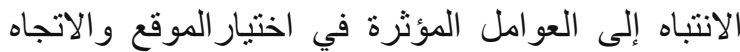

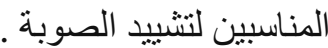
أـ الموقع : عند اختيار الموقع الأمثل لبناء الصوبة التبة

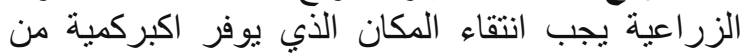
ضوء الثمس. ومن العو امل المؤثرة في ذللك طول الثئ النهار

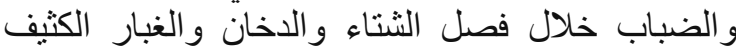

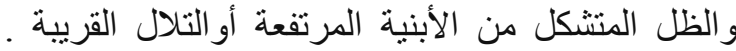

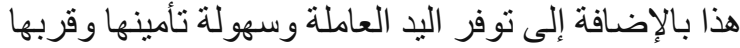
من موقع المشروع ، وذللك بعد أختيار أرض ذالت ذات تربة

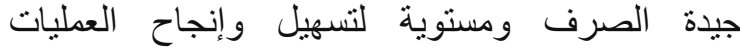

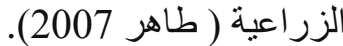

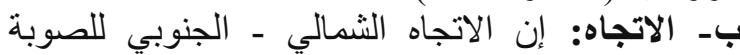

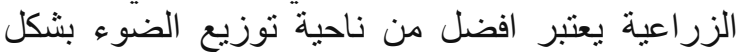

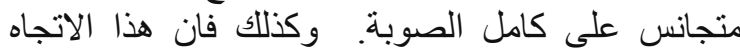

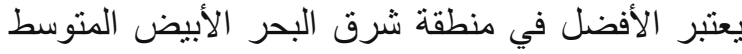

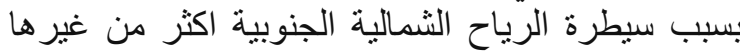

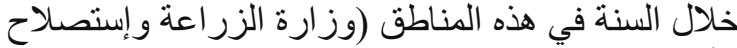
الأر اضى (2019).

والتشمل عناصر التكاليف مايلي : أولاً : التكاليف الثابتة :

أـ التكاليف الثابتة للبئر الجوفى ومحطة الطاقة الثمسية ومحطة التحلية : تبين بيانات الجدول رلئن رقم (2) إجمالى الجئي التكاليف الأستثمارية للبئر الجوفى وإقامة إنهة محطة الطاقة الثمسية وكذلك محطة تحلية المياه و إقامة عدد 6 خز انات مياه.

جدول (2): التكاليف الأستثمارية لبئر المياه ومحطة الطاقة الثمسية ومحطة التحلية.

\begin{tabular}{|c|c|}
\hline القيمة بالجنيه & البيان \\
\hline 815520 & ومحطة التكاليف الأستثمارية لبئز الثمسية المياه \\
\hline 139020 & 1 البئر \\
\hline 280000 & 2) محطة الطاقة الثمسية \\
\hline 300000 & 3)محطة التحلية \\
\hline 20000 & 4) الات ومعدات \\
\hline 76500 & 5) خز انات ومو اسير ومحابس \\
\hline
\end{tabular}

المصدر : بيانات الدر اسة الميدانية ومتوسط أسعار عامى 2017 ، 2018.

بـ التكاليف الثابتة لإنثاء عدد عشرة صوب زراعية : 35 × 10) 1- الهيكل الحديدى: وهئ وهوالهيكل الذى يلزم لاعطاء

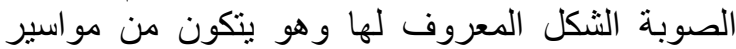

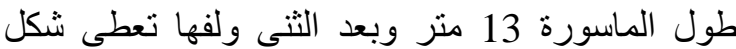

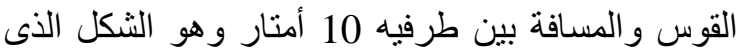

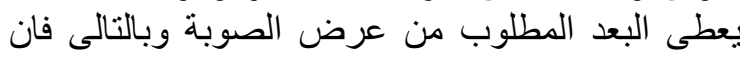

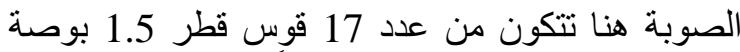
وسمك القوس 3 مم وتحتوى ايضاً على عدد 34 وتد، 


\begin{tabular}{|c|c|c|}
\hline 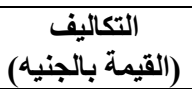 & البيان & ? \\
\hline 14500 & الهيكل الحديدى ( المو اسير والأوتاد المعدن) & 1 \\
\hline 7153.6 & الغطاء البلاستيك = 52.6 جنيه × 136 كجم & 2 \\
\hline 630 & سللك أو كبل الثند بين الأقو اس = 30 كجم × 21 جنبه & 3 \\
\hline 156 & خيوط التسلق = 12 كجم × 13 جنيه & 4 \\
\hline 400 & الأبو اب = 2 باب × 200 جنيه & 5 \\
\hline 200 & أجرة نقل & 6 \\
\hline 1000 & أجرة تركيب & 7 \\
\hline 300 & الأشر اف على التركيب الصوب & 8 \\
\hline 1000 & شبكة الرى الداخلية & 9 \\
\hline 75 & أجرة تركيب شبكة الرى & 10 \\
\hline 25414.6 & 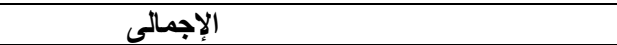 & \\
\hline
\end{tabular}

القيمة الاجمالية للتكاليف الثابتة لعدد عشرة صوب إلبه

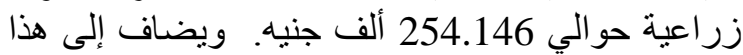

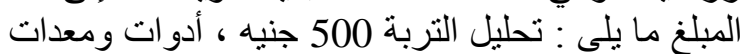

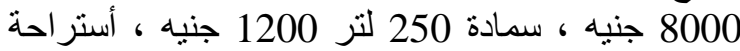
للعمال 4000 جنيه ، مخزن لكئل اللات و المعدات 25000 جنيه ، وبالتالى بلغت إجمالى هذه التكاليف 292.846 ألف جنيه .

إجمالى التكاليف الثابتة للمشروع وهى التكاليف التى سيتم سدادها مرة والمدة واحدة طو ال عمر المشروع ، وهى الأصول التى تكلفتها حوالى مالى

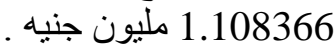
مخصص إهلاك رأس المال الثابت وهو عبارة عن قيمة التكاليف الثابتة مقسومة على على الثى

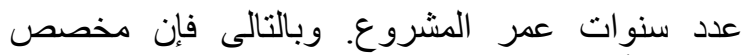

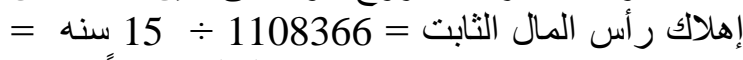

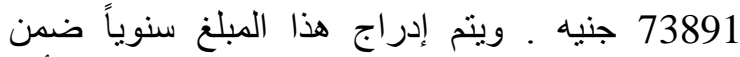

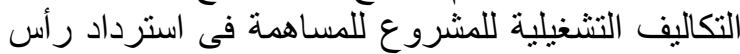
المال بعد إنتهاء الفترة التقديرية لعمر المشروع والثئي تبلغ 15 سنة . تلبكاء ثانياً: التكاليف المتغيرة :

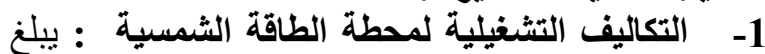

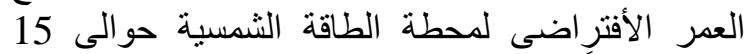

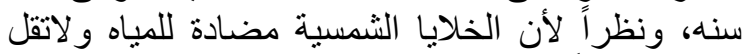

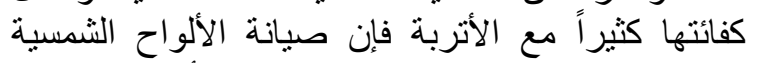

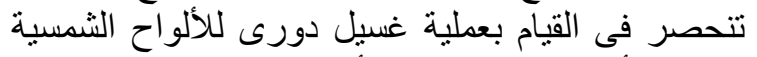

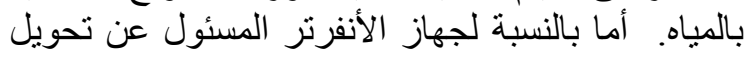

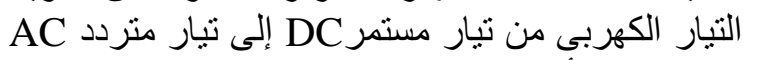

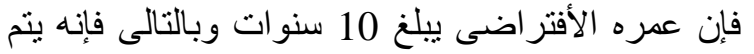
تغييره فى بداية العام الحادى عشر لتشغيل التشيل المشروع

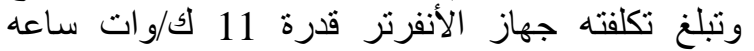
حو الى 45 ألف جنيه .

جدول (4) : التكاليف التثغيلية لمحطة الطاقة الثمسية .

\begin{tabular}{|c|c|c|}
\hline القيمة بالجنيه & البيان & p \\
\hline 5000 & تكلقة التشغيل والصيانة السنوية & 1 \\
\hline 45000 & تكلفة تغيير الأنفرتز كل 10 سنوات & 2 \\
\hline 15 & العمر الأفتر اضى للمحطة & 3 \\
\hline
\end{tabular}

التكلفة الاجمالية لنقل 10 صوب نحو 2000 جنيه . 9- الأدوات والمعدات الخاصة بالأعمال اليومية في الألئ المشروع: وهذه الادوات والاتوات والمعدات تشمل الأمل المعدات

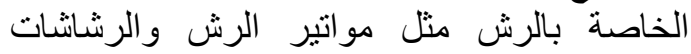

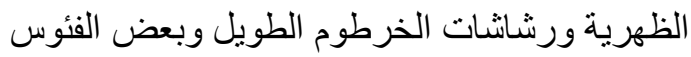
و الكوارك المختلفة وكل ماسبق من معدات النئ يعتمد لله مبلغ 8000 جنيه لكل المتطلبات .

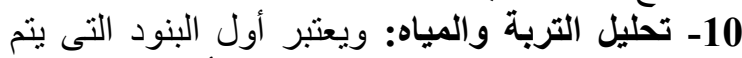

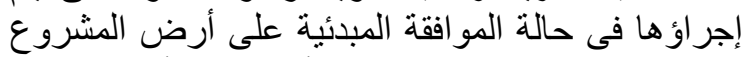

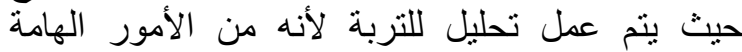

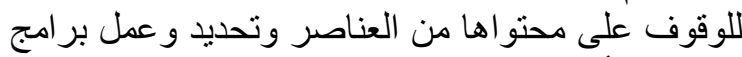

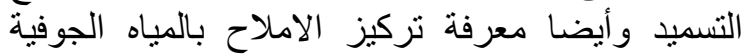

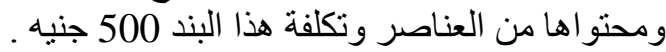

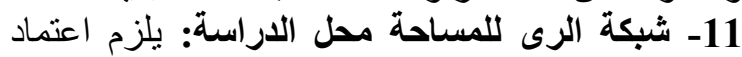

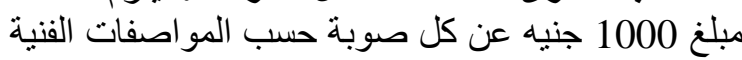
الخاصة بتركيب شبكة الرى بالتنقيط للمساحة محل

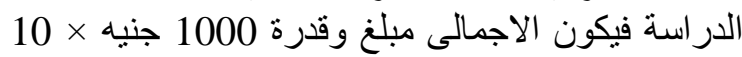

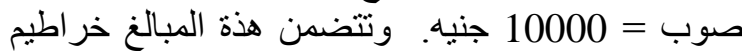

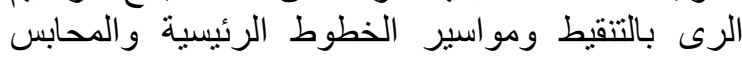
الرئيسية و الفر عيه ومنطلباتها الثنانوية.

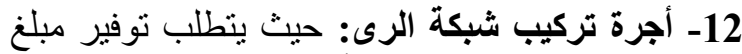

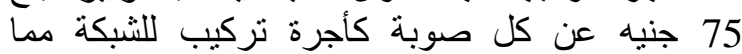

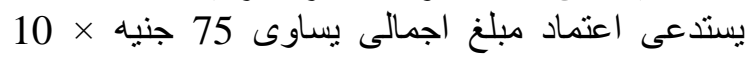

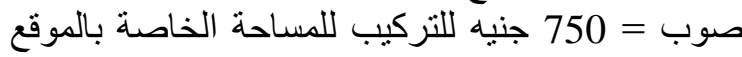

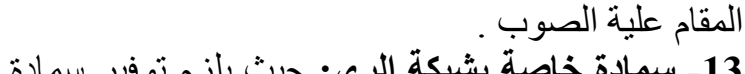

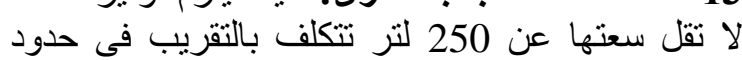

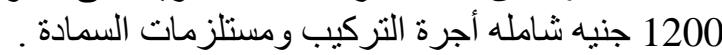

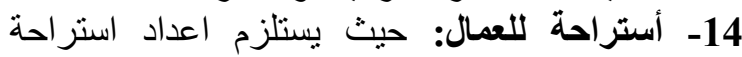

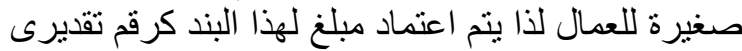

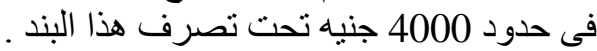

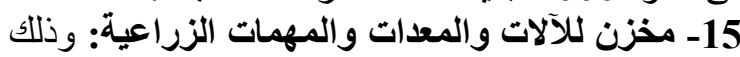

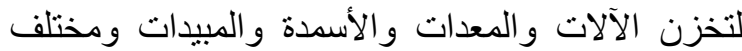

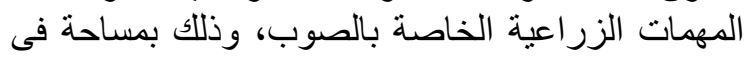

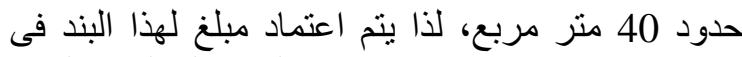

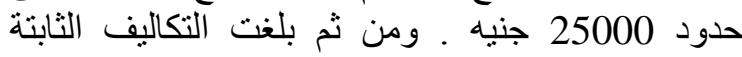
لإنشاء الصوبة الواحدة 25414.6 جنيه. و عليه تبلغ 
جنيه = 300 جنيه .

4- أسمدة ومبيدات: هذا البند يستلزم توفير مبلغ وقدره

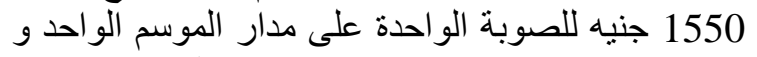

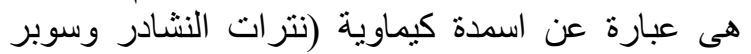

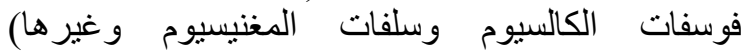
ومخصبات زر اعية ومبيدات وخلافة ، الأمر الذى يتطلب

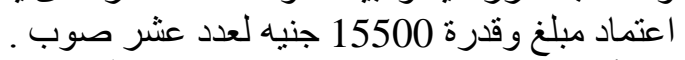

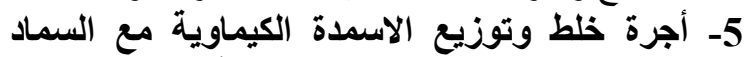

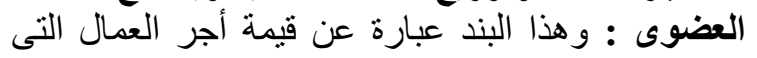

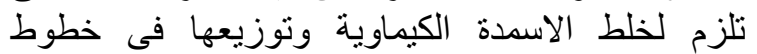

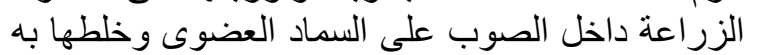

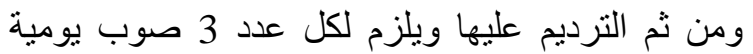

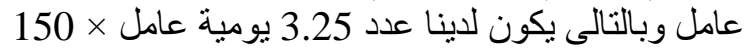

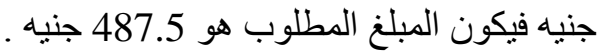
6- توريد البذور اللازمة للزيلة التراعة :

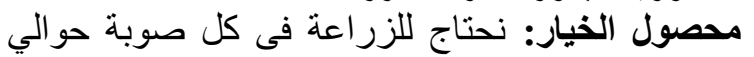

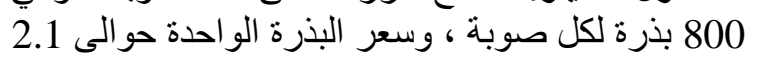

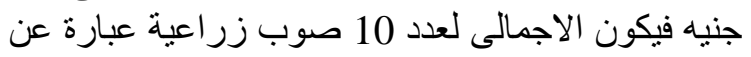

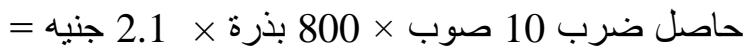
16800 جنيه وذللك لمحصول هوب الخيار .

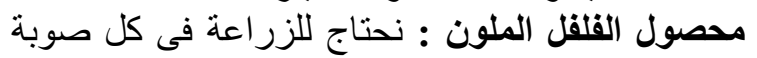

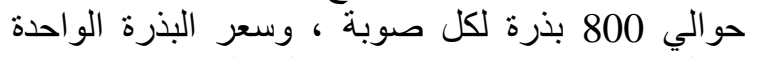

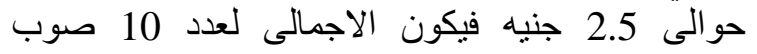

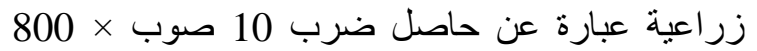

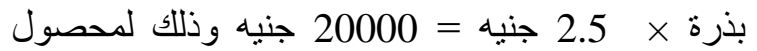

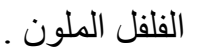
7-أجرة تحضين البذور بالمشتل: ويلزم لكل 200 بذرة

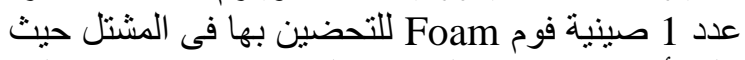
تبلغ أجرة تحضين الصينية الواحدة 20 جنيه. ويلزم التئل

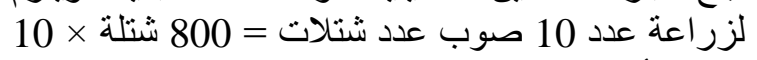

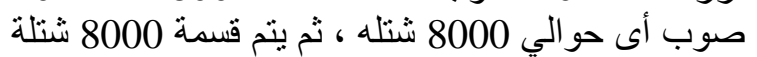

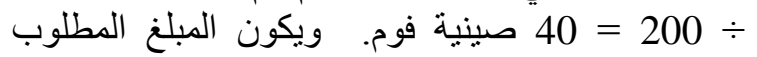

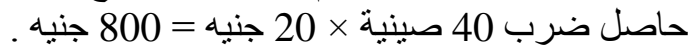

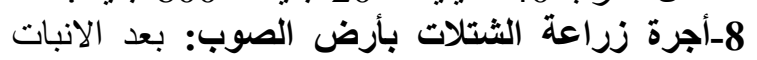

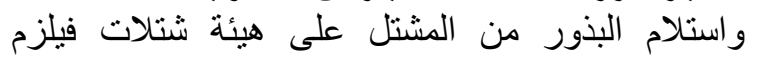

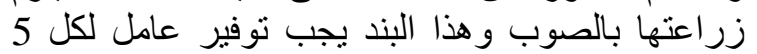

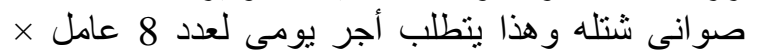
150 جنيه = 1200 جنيه ونيه -9 - أجور عمال دائمون : محصول الخيار: تحتاج كل 5 صوب دوب عامل دائم للمبانشرة

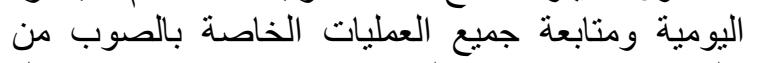

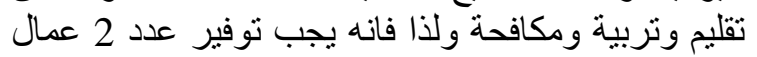

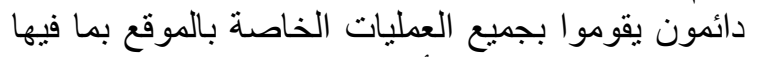

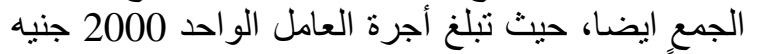

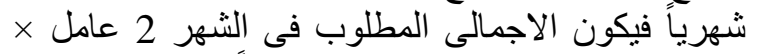

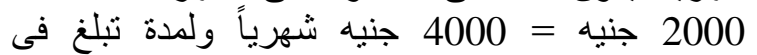
المتوسط 4 شهور عمل للموسم ، الأمر الذى بعتمد له له

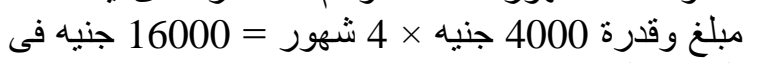

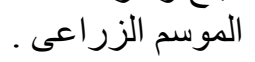
محصول الفلفل الملون: تحتاج كل عدد 5 صوب عامل

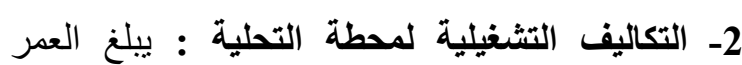

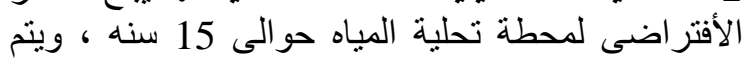
التعاقد مع الثركة الموردة للحططة التحلية على صيانة التيانة

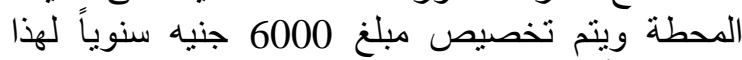

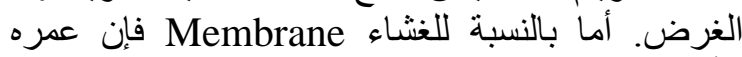
الأفتر اضى يبلغ 5 سنوات وبات بالتالى فيتم تغييره في بداية

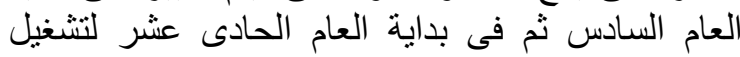
المشروع وتبلغ تكلفة تغييره فى كل فل مرة حوالى الى 1000

جنبه

\begin{tabular}{|c|c|c|}
\hline \multicolumn{3}{|c|}{ 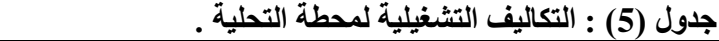 } \\
\hline القيمة بالجنيه & البيان & \\
\hline 6000 & تكلفة التشغيل والصيانة السنوية & 1 \\
\hline 1000 & تكلفة تغيير وحدات الغثاء & 2 \\
\hline 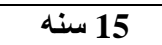 & العمر الأفتراضي & 3 \\
\hline
\end{tabular}

3- التكاليف التشغيلية لعدد عثرة صوب زراعية :

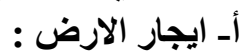

تبلغ إجمالى المساحة المخصصة ل للصوب المبار حو الي فدان تقريبا ، كما يتطلب المشروع المثر توفير مساحات أخرى تقدر

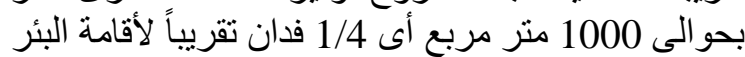

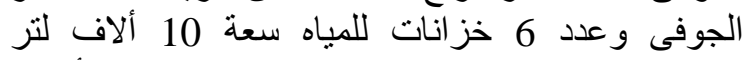

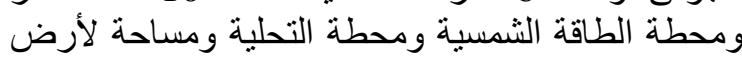

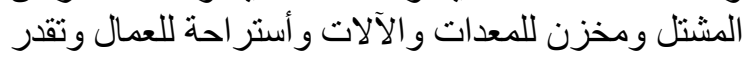
القيمة الإيجارية للفدان 6000 جنيه بالموات الصفات الصات السابقة

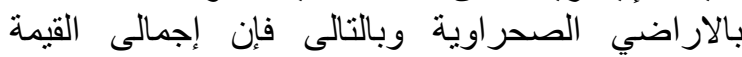
الايجارية للموقع = 1.25 فدان × 6000 جنيه = لالنية

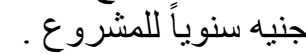
ب-العمليات الزراعية لمنئة

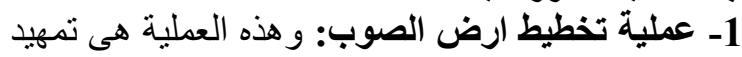

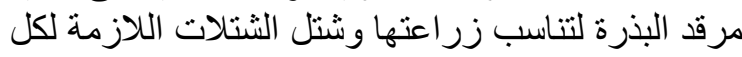

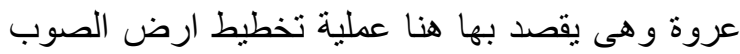

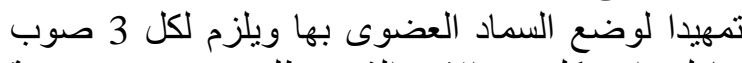

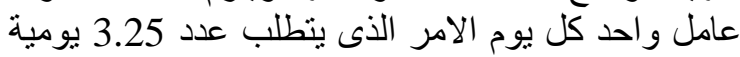

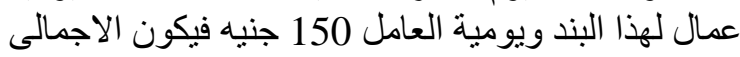

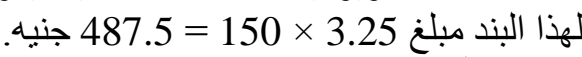

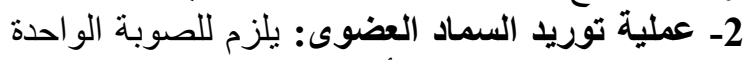

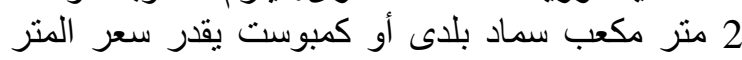

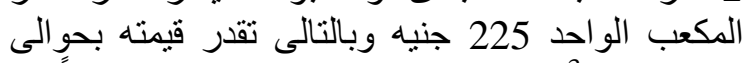

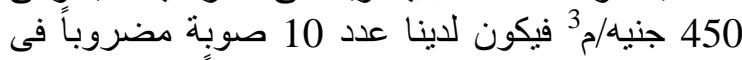
تكلفة سماد الصوبة الواحدة 450 جنياً 450 جنياً بقيمة إجمالية ( 4500

3-أجور عمالمة لتوزيع السماد العضوى فى خطوط:

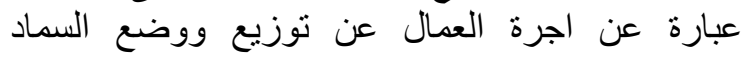

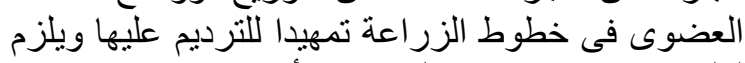

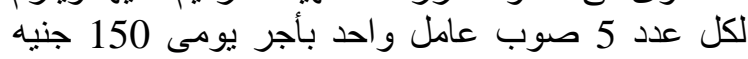
وبذلك يلزم مبلغ إجمالى يساوى عدد 2 عامل عالجر × 150 
10 صوب يبلغ عدد النباتات حوالي 8000 نبات فيكون 8000 نبات

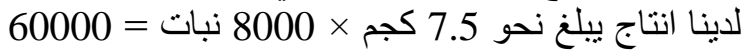

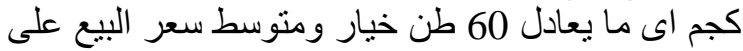

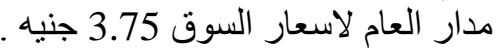
اجمالى عائد محصول الخيار هو 3.75 لأل 60000 كجم × 3.75

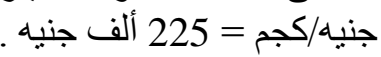
2-محصول الفلقل الملون : يبلغ متوسط التناج النبات

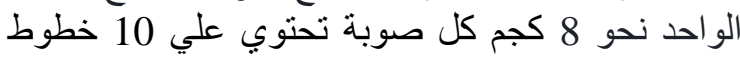
بكل خط 80 نبات لتبلغ عدد النباتات بالصوبة علب 800 نبات 8000 نبات في عدد 10 صوب ييلغ عدد النباتات حو الي 8000 ني 8000 نبات 800 نبات

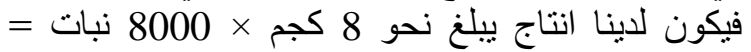

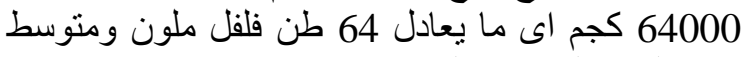
سعر البيع على مدار العام 8 جنيه . اجمالى عائد محصول الفلفل الملون هو 812 الفئ 64000 كجم ×

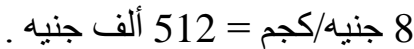

رابعاً : المؤشرات المالية لدراسة الجدوى :

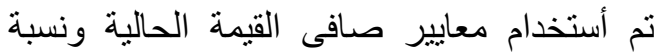

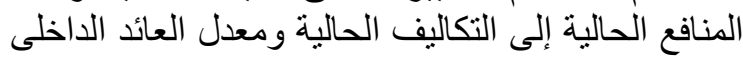

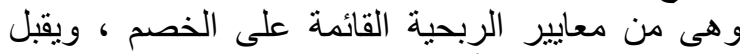

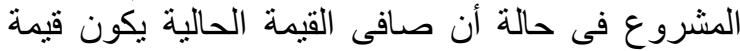

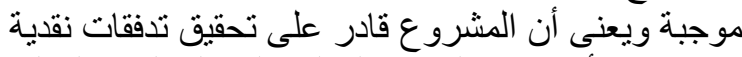
موجبة ، و أن نسبة المنافع الحالية إلى التكاليف الحالية الكالية

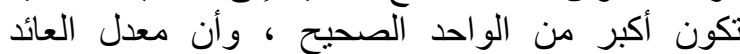

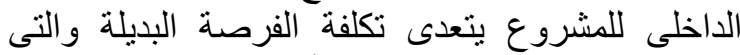

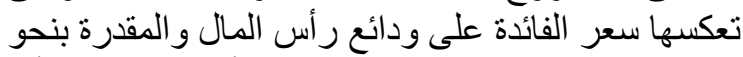

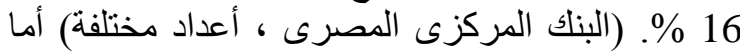

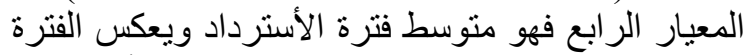

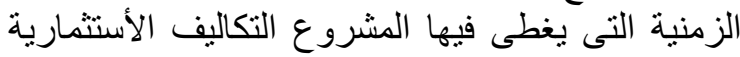
من خلال المجموع التراكمى لصنافى التهى التدفقات النقدية.

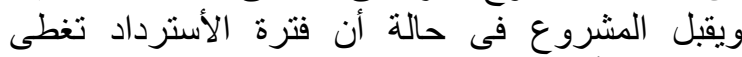

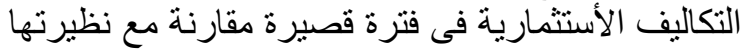

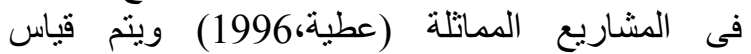

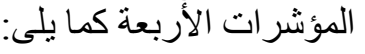

\begin{tabular}{|c|c|c|}
\hline & וصמ & \\
\hline بالألف جنيه & البيان & p \\
\hline 225 & 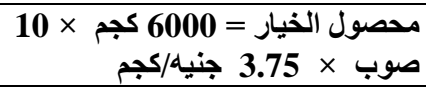 & 1 \\
\hline 512 & × 10 صول الفلفل × 8 جنون = 6400 كجم & 2 \\
\hline 737 & الإجمالى سنوياً & \\
\hline
\end{tabular}

المصدر : بيانات الاراسة الميدانية ومتوسط أسعار عامى 2017 ، 2018 ـ.

\footnotetext{
صافى القيمة الحالية Net Present Value (NPV) NPV $=\sum$ PVB $-\sum$ PVC

حيث NPV = صافى القيمة الحالية . PVB = PVC

نسبة المنافع الحالية إلى التكاليف الحالية

: Benefit/ Cost Ratio (B/C)
}

دائم للمباثرة اليومية ومتابعة جميع العمليات الخاصة

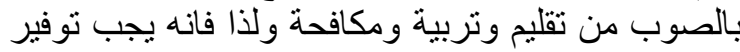

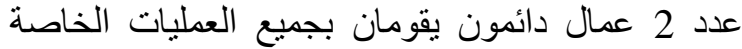

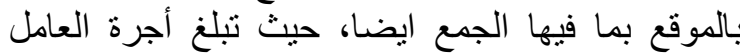

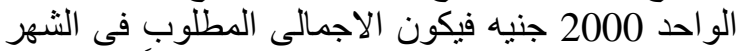

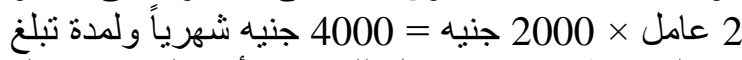

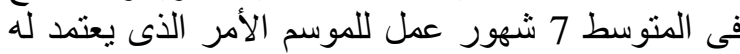

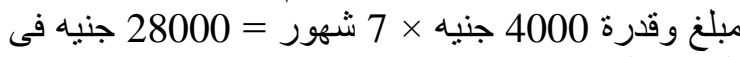

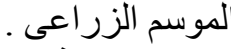

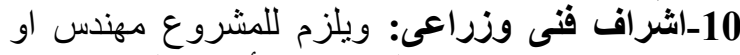

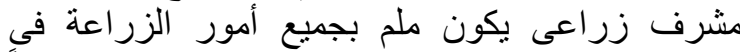
الصوب لا يقل راتبه مع الخبرة عن 3000 جنيه شهرياً

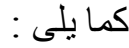
ـ محصول الخيار : تبلغ القيمة علي مدار الموسم الواحد

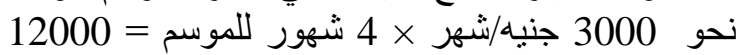
جنيه . . ـ محصول الفلفل الملون : تبلغ القيمة علي مدار الموسم الواحد نحو3000 جنيه/شهر × 7 × شهور اللموسم الفي 21000

11- صناديق التعبئة والتظليف المصنوعة من ورق

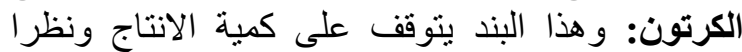

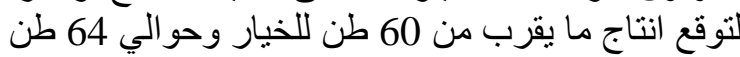

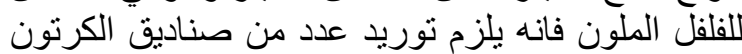

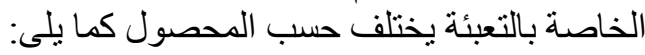

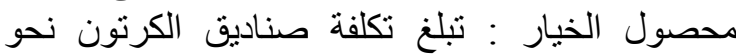

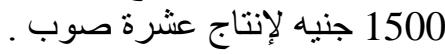
محصول الفلفل الملون : تبلغ تكلفة صناجة صناديق الكرتون نحو

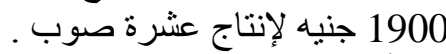
12-أجرة نقل الإنتحصول المحرة الى السوق: يختلف تقدير

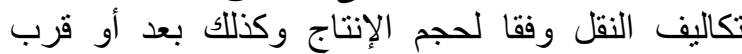

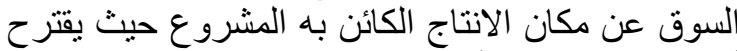

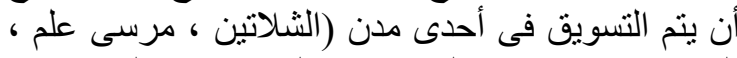

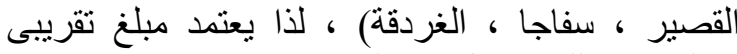
يختلف وفقا للمحصول كما يلى : ـمحصول الخيار : تبلغ القيمة نحو 8500 جنيه لعدد عشرة صوب زر اعية. ـمحصول الفلفل الملون : تبلغ القيمة نحو 10000 جنيه

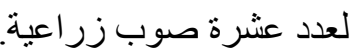

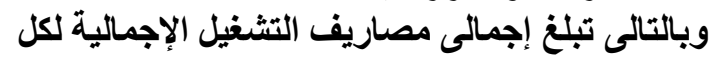
محصول بالدورة الإنتاجية كما يلى : ـمحصول الخيار = 80.575 ألف جنيه ونيه وذلك لعدد

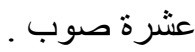
-محصول الفلفل الملون = 108.550 ألف جنيه وذلك

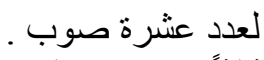
تالثاً : إيرادات المشروع :

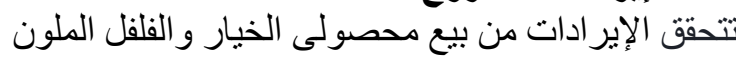

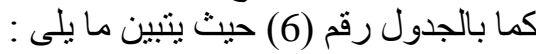

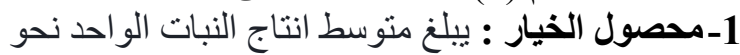
7.5 كجم ، كل صولة 7.5 80 نبات لتبلغ عدد النباتات بالصوبة 800 نبات في عدد 


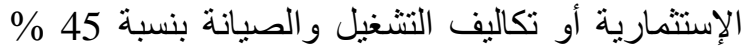

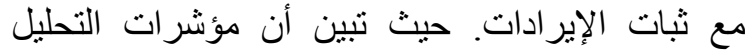

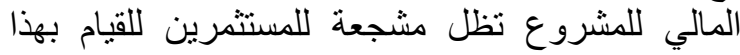

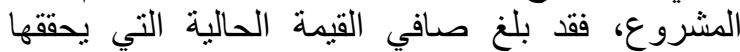
14.827 ألف جنيه، كما أن نسبة المنافع الحالية إلي الئية

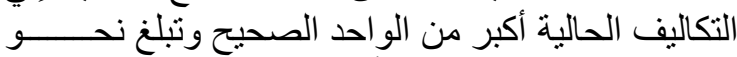

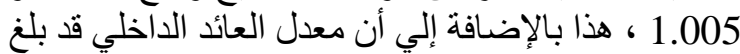
18.26 \% ، وبالنسبة لمعيار فترة إسترداد رأس المال المبال

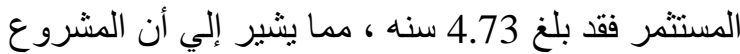
ماز ال ذال ذو جدوي إقتصادية.

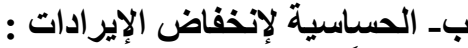

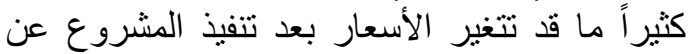

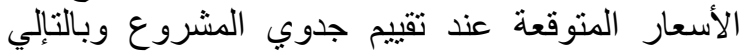

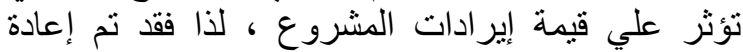

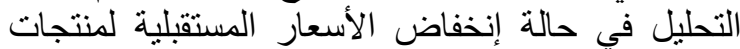

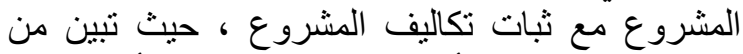

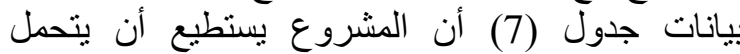

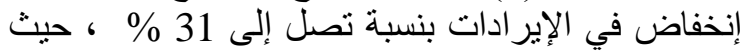

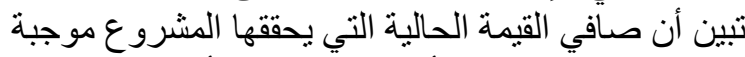

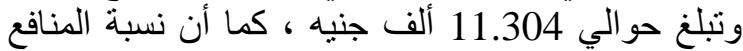
الحالية إلي التكاليف الحالية أكبر من الوالئ الحد الصحيح

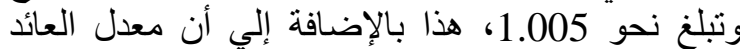
الداخلي قد بلغ 18.29 \% ، و وبالنسبة لمعيار فترة إسترداد الفياد

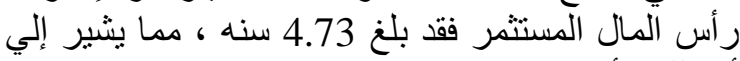
أن تلك الأنشطة ذات جدوي إقتصادية.

ج- الحساسية لزيادة التكاليف وإنخفاض الإيرادات التاتئ :

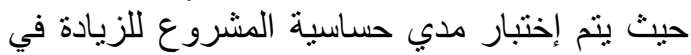

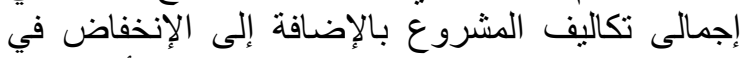

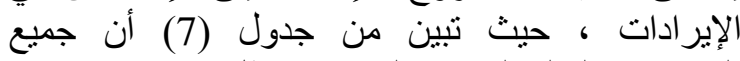

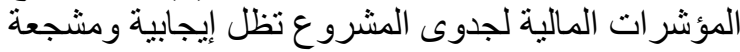

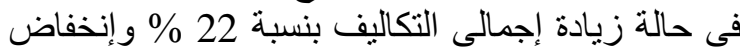
إيرادات المشروع أيضاً بنسبة 16\%

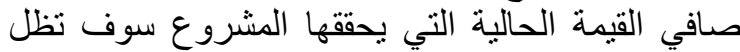

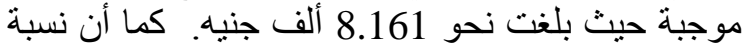

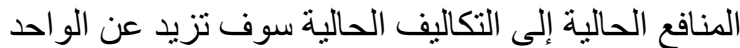

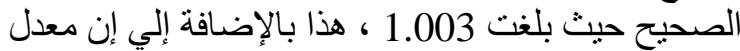
العائد الداخلي قد بلغ 18.17 \% ، وبلغ بالنسبة لمعيار فترة

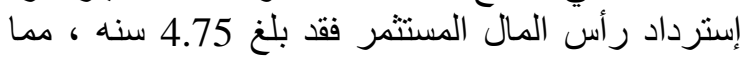
يشير إلي أن هذا النشاط ما زال مشجع للأستثمار تحت

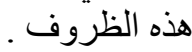

دـ الحساسية لقصر عمر المشروع : تبين من بيانات جدول (7) أن المشروع المثرو يتحمل

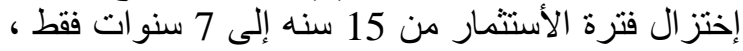

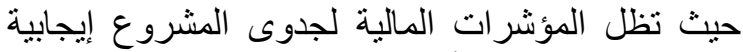

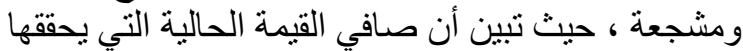

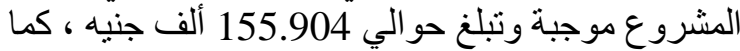

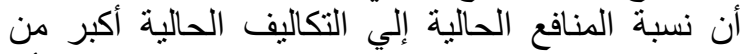

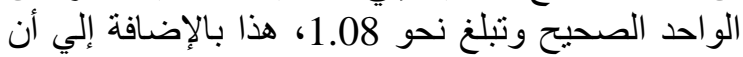

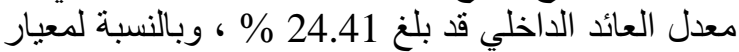
فترة إسترداد ر أس المال المستثمر فقد بلغ 2.93 سنه .
Benefit $/$ Cost Ratio = PVB $/$ PVC

$$
\begin{aligned}
& \text { حيث PVB = القيمة الحالية للإير ادات . } \\
& \text { PVC }
\end{aligned}
$$

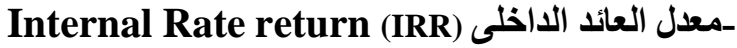
IRR = $\mathbf{r}_{1+}\left(\mathbf{r}_{2}-\mathbf{r}_{1}\right)\left(\mathrm{NPV}_{1)} /\left(\mathrm{NPV}_{1}-\mathrm{NPV}_{2}\right)\right.$

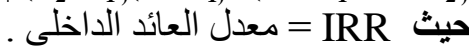
rer1 سعر الخصم الأعلى = r

= NPV

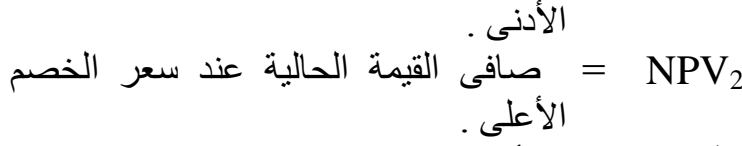
فترة استرداد رأس المال (CPBP) Back = إجمالى التكاليف الأستثمارية / متوسط الربح السنوى (Georgakellos2009). وتثير بيانات الجدول رقم (7) إلى المؤشر ات المالية

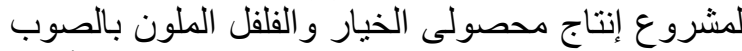

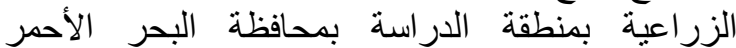
بأستخدام تقنية الطاقة الثمسية فى تحلية مياه الآبار ، وذللك عند معدل خصم 18 \% حيث تبين ما يلى : -بلغ صافى القيمة الحالية Net Present Value حو الى 280.958 (NPV) جدوى الاستثمار فى هذا النشاط.

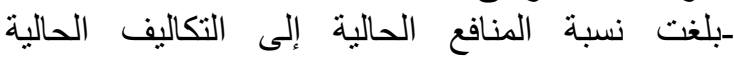
نحن Benefit/ Cost Ratio (B/C) من الواحد الصحيح وهو ما يدل على جدوى الاستثمار

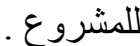

Internal Rate return بلغ معدل العائد الداخلى ألخى نحو 40.82 \% أى يزيد عن منوسط سعر الفائدة السائد و البالغ نحو 16 \% مما يؤكد جدوى الاستثمار فى مئر

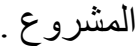

Capital Pay (CPBP) بلغت فترة استرداد ر أس المال

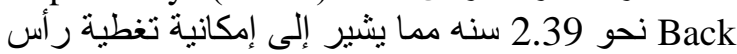
المال المستثر في خلال عامين وخمسة أثشهر فقط . خامساً : تحليل الحساسية Sensitivity Analysis إن من بين مزايا التحليل المالي للمشروع إمكانيل إلمانية

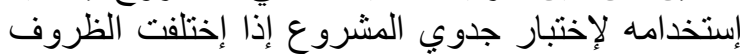

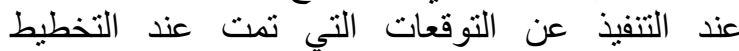

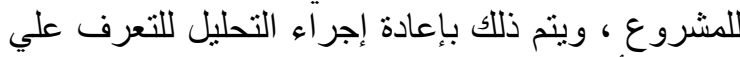

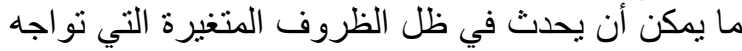

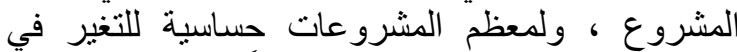

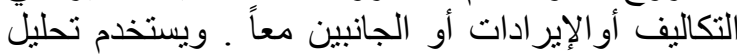

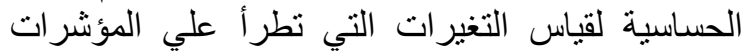

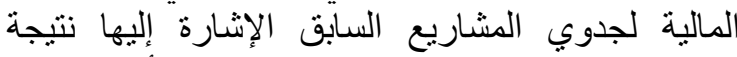
التوقعات بحدوث تغير في تكاليف المشروع الأبنارة ألو في سعر

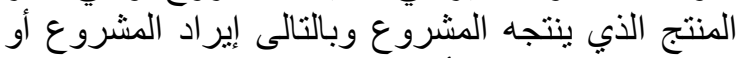

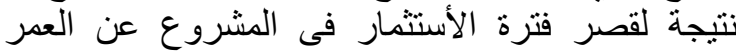

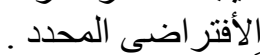
أً الحساسية للزيادة في التكاليف:

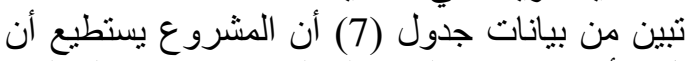

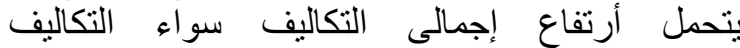


جذول (7) : ملخص مؤشرات التحليل المالى لاراسة جذوى المشروع.

\begin{tabular}{|c|c|c|c|c|c|}
\hline \multicolumn{4}{|c|}{ تحليل الحساسية } & \multirow[b]{2}{*}{ 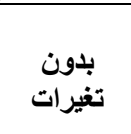 } & \multirow[b]{2}{*}{ مؤشرات التحليل المالطى التقييم } \\
\hline أختزال عمر المشروع 7 سنوات & و زيادة التكاليف 22 \% 16 \% & $\begin{array}{l}\text { إنخفاض الإيراد } 31 \\
\text { \% }\end{array}$ & زيادة التكاليف 45 & & \\
\hline 155.904 & 8.161 & 11.304 & 14.827 & 980.958 & صافى القيمة الحالية \\
\hline 1.08 & 1.003 & 1.005 & 1.005 & 1.46 & التكاليف المنافع الحالية (\%) / \\
\hline 24.41 & 18.17 & 18.29 & 18.26 & 40.82 & معدل العائد الداخلى(\%) \\
\hline 2.93 & 4.75 & 4.73 & 4.73 & 2.39 & فترة الأسترداد (سنـه) \\
\hline
\end{tabular}

ـ قيام الدولة بجذب وتحفيز القطاع الخاص للأستثمار فى الطي مجال الطاقة الشمسية وتحلية المياه .

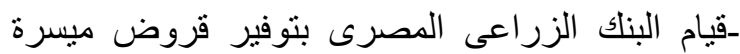
لغرض إنشاء الصوب الزرب الزر اعية . -جذب المستثرين وشباب الخرجين للتوسع فى إستخدام

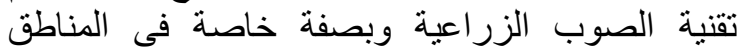

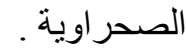

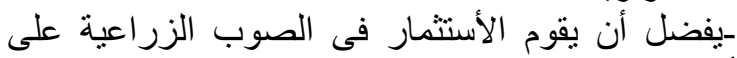

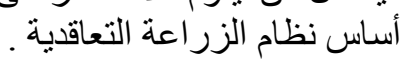

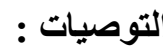

ـالصوب الزر اعية وجدو اها الأقتصادية.

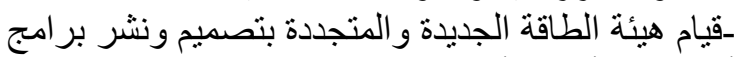

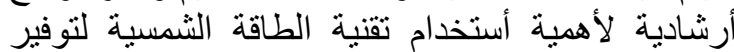

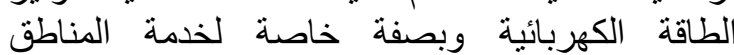

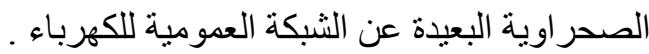

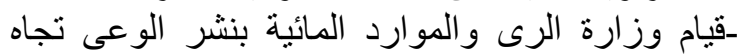
إستخدام تقنية تحلية مباه الآبار فى المناطق الصحر الصحر اوية و الساحلية . 


\section{الملاحق}

جلول (1) : التحليل المالى للتدفقات النقدية الخارجة والداخلة لمشروع إنتاج محصولى الخيار والفلقل الملون من فدان صوب بأستخدام تقنيات الطاقة الثمسية لتوليد الطاقة الكهربائية وتحلية مياه الآبار على مدى

\begin{tabular}{|c|c|c|c|c|c|c|c|c|c|c|c|c|c|c|c|c|}
\hline & & & & & & & & & & & & & & \multicolumn{3}{|c|}{15 سنه } \\
\hline الإجمالى & 15 & 14 & 13 & 12 & 11 & 10 & 9 & 8 & 7 & 6 & 5 & 4 & 3 & 2 & 1 & البيان \\
\hline \multicolumn{17}{|c|}{ التئفقات النقاية الخارجة } \\
\hline & 0 & 0 & 0 & 0 & 0 & 0 & 0 & 0 & 0 & 0 & 0 & 0 & 0 & 0 & 1108366 & التكاليف الأستشمارية \\
\hline & 200125 & 200125 & 200125 & 246125 & 271661 & 200125 & 200125 & 200125 & 201125 & 271661 & 200125 & 200125 & 200125 & 200125 & 0 & تكاليف التثغيل \\
\hline & 73891 & 73891 & 73891 & 73891 & 73891 & 73891 & 73891 & 73891 & 73891 & 73891 & 73891 & 73891 & 73891 & 73891 & 0 & الأهلاك \\
\hline & 274016 & 274016 & 274016 & 320016 & 345552 & 274016 & 274016 & 274016 & 275016 & 345552 & 274016 & 274016 & 274016 & 274016 & 1108366 & إجمالى التانفرقات النقلقية \\
\hline \multicolumn{17}{|c|}{ التنفقات النقسية الداخلة } \\
\hline & 737000 & 737000 & 737000 & 737000 & 737000 & 737000 & 737000 & 737000 & 737000 & 737000 & 737000 & 737000 & 737000 & 737000 & 0 & إجمالى الثاذفلقات النقاية \\
\hline 3127916 & 61551 & 72631 & 85704 & 101131 & 119334 & 140815 & 166161 & 196070 & 231363 & 273008 & 322149 & 380136 & 448561 & 529302 & 0 & 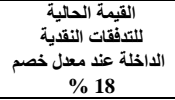 \\
\hline & 462984 & 462984 & 462984 & 416984 & 391448 & 462984 & 462984 & 462984 & 461984 & 391448 & 462984 & 462984 & 462984 & 462984 & -1108366 & صافى التثفقات النقدية \\
\hline 980958 & 38667 & 45627 & 53839 & 57218 & 63383 & 88460 & 104383 & 123171 & 145028 & 145005 & 202375 & 238802 & 281786 & 332508 & -939293 & 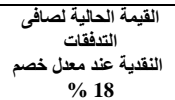 \\
\hline
\end{tabular}

المصدر : جمعت وحسبت من بيانات البحث بأستخدام برنامج Excel . 


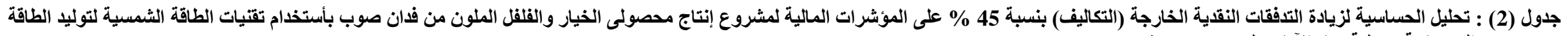

\begin{tabular}{|c|c|c|c|c|c|c|c|c|c|c|c|c|c|c|c|c|}
\hline & & & & & & & & & & & & \multicolumn{5}{|c|}{ الكهربائية وتحلية مياه الآبار على مدى 15 سنه } \\
\hline 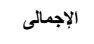 & 15 & 14 & 13 & 12 & 11 & 10 & 9 & 8 & 7 & 6 & 5 & 4 & 3 & 2 & 1 & البيان \\
\hline \multicolumn{17}{|c|}{ التصفقات النقية الخارجة } \\
\hline & $\mathbf{0}$ & $\mathbf{0}$ & $\mathbf{0}$ & $\mathbf{0}$ & $\mathbf{0}$ & $\mathbf{0}$ & $\mathbf{0}$ & $\mathbf{0}$ & $\mathbf{0}$ & $\mathbf{0}$ & $\mathbf{0}$ & $\mathbf{0}$ & $\mathbf{0}$ & 0 & 1607131 & التكاليف الأستثارية \\
\hline & 290181 & 290181 & 290181 & 356881 & 393908 & 290181 & 290181 & 290181 & 291631 & 393908 & 290181 & 290181 & 290181 & 290181 & $\mathbf{0}$ & ت تكاليف التثغيل \\
\hline & 107142 & 107142 & 107142 & 107142 & 107142 & 107142 & 107142 & 107142 & 107142 & 107142 & 107142 & 107142 & 107142 & 107142 & 0 & الأهلاك \\
\hline & 397323 & 397323 & 397323 & 464023 & 501050 & 397323 & 397323 & 397323 & 398773 & 501050 & 397323 & 397323 & 397323 & 397323 & 1607131 & إجمالى الثتارفقاتة النقلقية \\
\hline 3113089 & 33183 & 39156 & 46204 & 63673 & 81130 & 75914 & 89579 & 105703 & 125185 & 185605 & 173674 & 204935 & 241823 & 285351 & 1361975 & 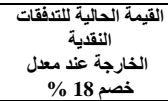 \\
\hline \multicolumn{17}{|c|}{ التدفقات النقية الداخلة } \\
\hline & 737000 & 737000 & 737000 & 737000 & 737000 & 737000 & 737000 & 737000 & 737000 & 737000 & 737000 & 737000 & 737000 & 737000 & 0 & إجمالى الثنففلقة النقلية \\
\hline \multirow[t]{2}{*}{3127916} & 61551 & 72631 & 85704 & 101131 & 119334 & 140815 & 166161 & 196070 & 231363 & 273008 & 322149 & 380136 & 448561 & 529302 & 0 & 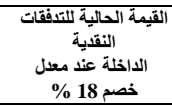 \\
\hline & 339677 & 339677 & 339677 & 272977 & 235950 & 339677 & 339677 & 339677 & 338227 & 235950 & 339677 & 339677 & 339677 & 339677 & -1607131 & صافى التنفقات النقية \\
\hline 14827 & 28368 & 33475 & 39500 & 37458 & 38205 & 64900 & 76582 & 90367 & 106178 & 87403 & 148476 & 175202 & 206738 & 243951 & -1361975 & 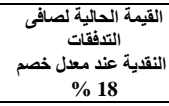 \\
\hline
\end{tabular}




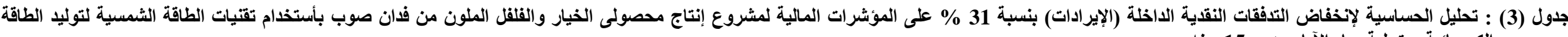

\begin{tabular}{|c|c|c|c|c|c|c|c|c|c|c|c|c|c|c|c|c|}
\hline الإجمالى & 15 & 14 & 13 & 12 & 11 & 10 & 9 & 8 & 7 & 6 & 5 & 4 & 3 & 2 & 1 & البيان \\
\hline \multicolumn{17}{|c|}{ التدفقات النقدية الخارجة } \\
\hline & 0 & 0 & 0 & 0 & 0 & 0 & 0 & 0 & 0 & 0 & 0 & 0 & 0 & 0 & 1108366 & الأنتثماليفية \\
\hline & 200125 & 200125 & 200125 & 246125 & 271661 & 200125 & 200125 & 200125 & 201125 & 271661 & 200125 & 200125 & 200125 & 200125 & 0 & تكاليف التثشغيل \\
\hline & 73891 & 73891 & 73891 & 73891 & 73891 & 73891 & 73891 & 73891 & 73891 & 73891 & 73891 & 73891 & 73891 & 73891 & $\mathbf{0}$ & الأهلاك \\
\hline & 274016 & 274016 & 274016 & 320016 & 345552 & 274016 & 274016 & 274016 & 275016 & 345552 & 274016 & 274016 & 274016 & 274016 & 1108366 & إلنقالية الخارجة التفات \\
\hline 2146958 & 22885 & 27004 & 31865 & 43912 & 55951 & 52355 & 61779 & 72899 & 86334 & 128003 & 119775 & 141334 & 166775 & 196794 & 939293 & 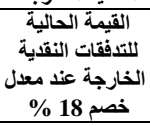 \\
\hline \multicolumn{17}{|c|}{ التدفقات النقاية الداخلة } \\
\hline & 508530 & 508530 & 508530 & 508530 & 508530 & 508530 & $\mathbf{5 0 8 5 3 0}$ & 508530 & 508530 & 508530 & $\mathbf{5 0 8 5 3 0}$ & 508530 & 508530 & $\mathbf{5 0 8 5 3 0}$ & 0 & إلنقالية اللاخدلةًات \\
\hline \multirow[t]{2}{*}{2158262} & 42470 & 50115 & 59136 & 69780 & 82341 & 97162 & 114651 & 135288 & 159640 & 188376 & 222283 & 262294 & 309507 & 365218 & $\mathbf{0}$ & اللتدفقات النقالية \\
\hline & 234514 & 234514 & 234514 & 188514 & 162978 & 234514 & 234514 & 234514 & 233514 & 162978 & 234514 & 234514 & 234514 & 234514 & -1108366 & صافي التدفقّات \\
\hline 11304 & 19586 & 23111 & 27271 & 25868 & 26389 & 44807 & 52873 & 62390 & 73306 & 60372 & 102508 & 120960 & 142732 & 168424 & -939293 & 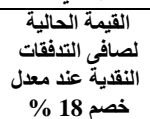 \\
\hline
\end{tabular}




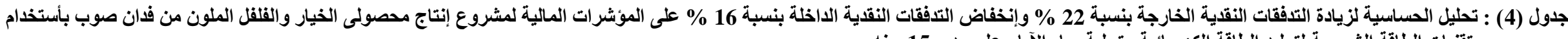

\begin{tabular}{|c|c|c|c|c|c|c|c|c|c|c|c|c|c|c|c|c|}
\hline ل الإجمالى & 15 & 14 & 13 & 12 & 11 & 10 & 9 & 8 & 7 & 6 & 5 & 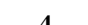 & 3 & 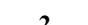 & 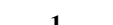 & 1. \\
\hline \multicolumn{17}{|c|}{ التدفقات النقدية الخارجة } \\
\hline & $\mathbf{0}$ & $\mathbf{0}$ & $\mathbf{0}$ & $\mathbf{0}$ & $\mathbf{0}$ & $\mathbf{0}$ & $\mathbf{0}$ & $\mathbf{0}$ & 0 & $\mathbf{0}$ & $\mathbf{0}$ & $\mathbf{0}$ & $\mathbf{0}$ & $\mathbf{0}$ & 1352207 & الأنكاليفية \\
\hline & 244153 & 244153 & 244153 & 300273 & 331426 & 244153 & 244153 & 244153 & 245373 & 331426 & 244153 & 244153 & 244153 & 244153 & 0 & تكاليف التشغيل \\
\hline & 90147 & 90147 & 90147 & 90147 & 90147 & 90147 & 90147 & 90147 & 90147 & 90147 & 90147 & 90147 & 90147 & 90147 & 0 & الأهلاك \\
\hline & 334300 & 334300 & 334300 & 390420 & 421573 & 334300 & 334300 & 334300 & 335520 & 421573 & 334300 & 334300 & 334300 & 334300 & 1352207 & 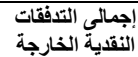 \\
\hline 2619289 & 27919 & 32945 & 38875 & 53573 & 68261 & 63873 & 75370 & 88936 & 105328 & 156164 & 146125 & 172428 & 203465 & 240089 & 1145938 & 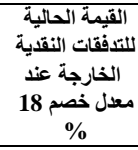 \\
\hline \multicolumn{17}{|c|}{ التدفقات النقدية الداخلة } \\
\hline & 619080 & 619080 & 619080 & 619080 & 619080 & 619080 & 619080 & 619080 & 619080 & 619080 & 619080 & 619080 & 619080 & 619080 & $\mathbf{0}$ & الجنقالية الدتلفقات \\
\hline \multirow[t]{2}{*}{2627450} & 51703 & 61010 & 71991 & 84950 & 100241 & 118284 & 139575 & 164699 & 194345 & 229327 & 270606 & 319315 & 376791 & 444614 & $\mathbf{0}$ & 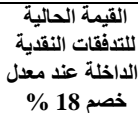 \\
\hline & 284780 & 284780 & 284780 & 228660 & 197507 & 284780 & 284780 & 284780 & 283560 & 197507 & 284780 & 284780 & 284780 & 284780 & -1352207 & صافي التصفقات \\
\hline 8161 & 23784 & 28065 & 33116 & 31377 & 31980 & 54411 & 64205 & 75762 & 89017 & 73163 & 124480 & 146887 & 173326 & 204525 & -1145938 & 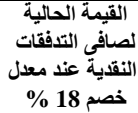 \\
\hline
\end{tabular}




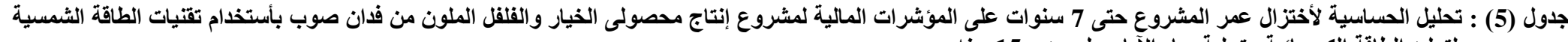

\begin{tabular}{|c|c|c|c|c|c|c|c|c|}
\hline الإجمالى & 7 & 6 & 5 & 4 & 3 & 2 & 1 & البيان \\
\hline \multicolumn{9}{|c|}{ التدفقات النقدية الخارجة } \\
\hline & 0 & 0 & 0 & 0 & 0 & 0 & 1108366 & التكاليف الأستثمارية \\
\hline & 201125 & 271661 & 200125 & 200125 & 200125 & 200125 & 0 & تكاليف التشغيل \\
\hline & 158338 & 158338 & 158338 & 158338 & 158338 & 158338 & 0 & الأهلاك \\
\hline & 359463 & 429999 & 358463 & 358463 & 358463 & 358463 & 1108366 & إجمالى التدفقات النقدية الخارجة \\
\hline 2028616 & 112844 & 159285 & 156687 & 184891 & 218172 & 257443 & 939293 & 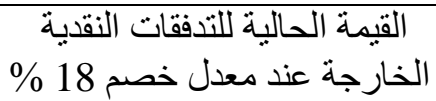 \\
\hline \multicolumn{9}{|c|}{ التدفقات النقية الداخلة } \\
\hline & 737000 & 737000 & 737000 & 737000 & 737000 & 737000 & 0 & إجمالى التدفقات النقدية الداخلة \\
\hline \multirow[t]{2}{*}{2184520} & 231363 & 273008 & 322149 & 380136 & 448561 & 529302 & 0 & 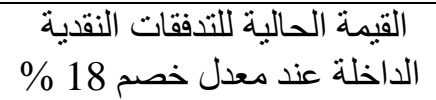 \\
\hline & 377537 & 307001 & 378537 & 378537 & 378537 & 378537 & -1108366 & صافى التدفقات النقدية \\
\hline 155904 & 118518 & 113723 & 165462 & 195245 & 230389 & 271859 & -939293 & 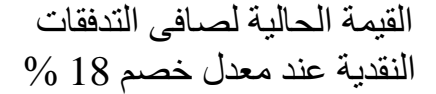 \\
\hline
\end{tabular}


الأقتصاد الزر اعى ، كلية الزر اعة ، جامعة عين

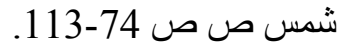

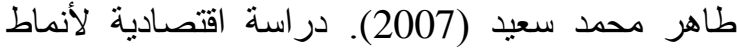

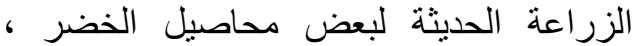
رسالة ماجستير ، قسم الأقتصاد الزر اعلى لاعى ، كلية

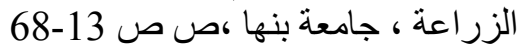

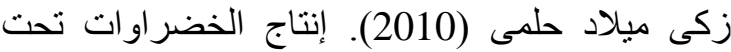
الصوب ، قسم الزر اعات المحمية ، معهد بحوث البساتين ، مركز البحوث الزر الزية ص ص ص 5.14

وزارة الزراعة وأستصلاح الأراضى(2009). مجلس البحوث الزراعية والتنمية ، استر اتيجية التنمية

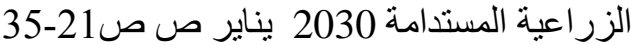

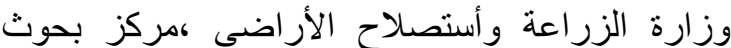
الصحر اء (2019). إستخدامات الطاقة الجديدة

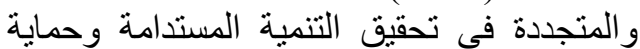

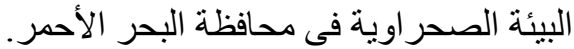

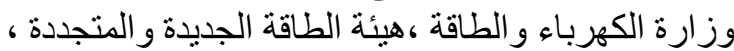
التقرير السنوى ، اعداد مختلفة (2010- 2017).

\section{EFERENCES}

Bishay Adly (1986). "Protected Agriculture and Desert development". National Workshop on Protected Agriculture. Organised by UN/FAO/UNDP. December. 1986.

Georgakellos D. A. and Marcis A. M. (2009). Application of the semantic learning approach in the feasibility studies preparation training process. Information Systems Management 26 (3) 231-240.

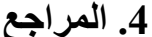

أبو العلا أشرف (2002). الكفاءة الاقتصادية لأهم الهم

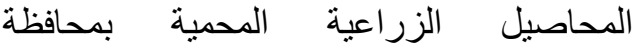

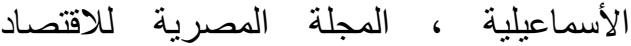

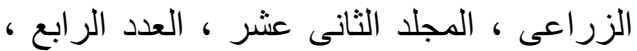

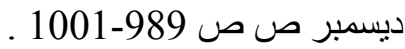

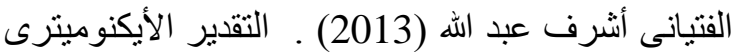

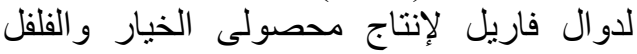
بالصوب الزراعية بمحافظة الدقهلية ، الإناجة المجلة

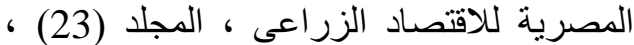
العدد (4) ، ديسمبر 2013ص صلصدياد صل 1001. 1569

الزنط أويس عطوه (1992). أسس تقييم المشروعات الأرات ودر اسات جدوى الأستثمار ، المكتبة الأكاديمية الفية

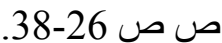

شمس الدين إلهام نسيم (2011-). إقتصاديات إنتاج بعض

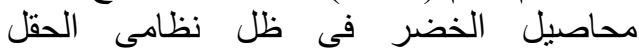
المكثوف و الصوب فى محافظة الدقهلية ، رسالة

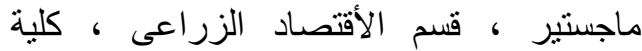

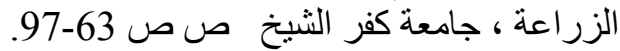
البنك المركزى المصرى ، النشرة الإحصائية الثهرية الثرية ، أعداد مختلفة .

الجهاز المركزى للتعبئة العامة و الأحصاء (2015). در اسة مستقبل الطاقة الثمسية فى مصر الأمر ، مارس

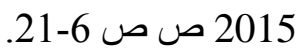

محمد خالد عبد الحميد (2012). اقتصاديات الطاقة الثنمسية في مصر " دراسة داسة مقارنة ودراسة قياسية " ، رسالة دكتور اة ، كلية التجارة ، جامعة ودية

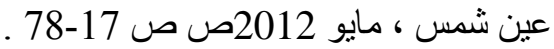

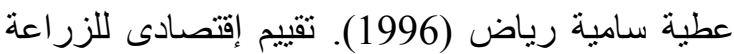

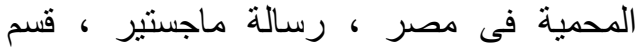

